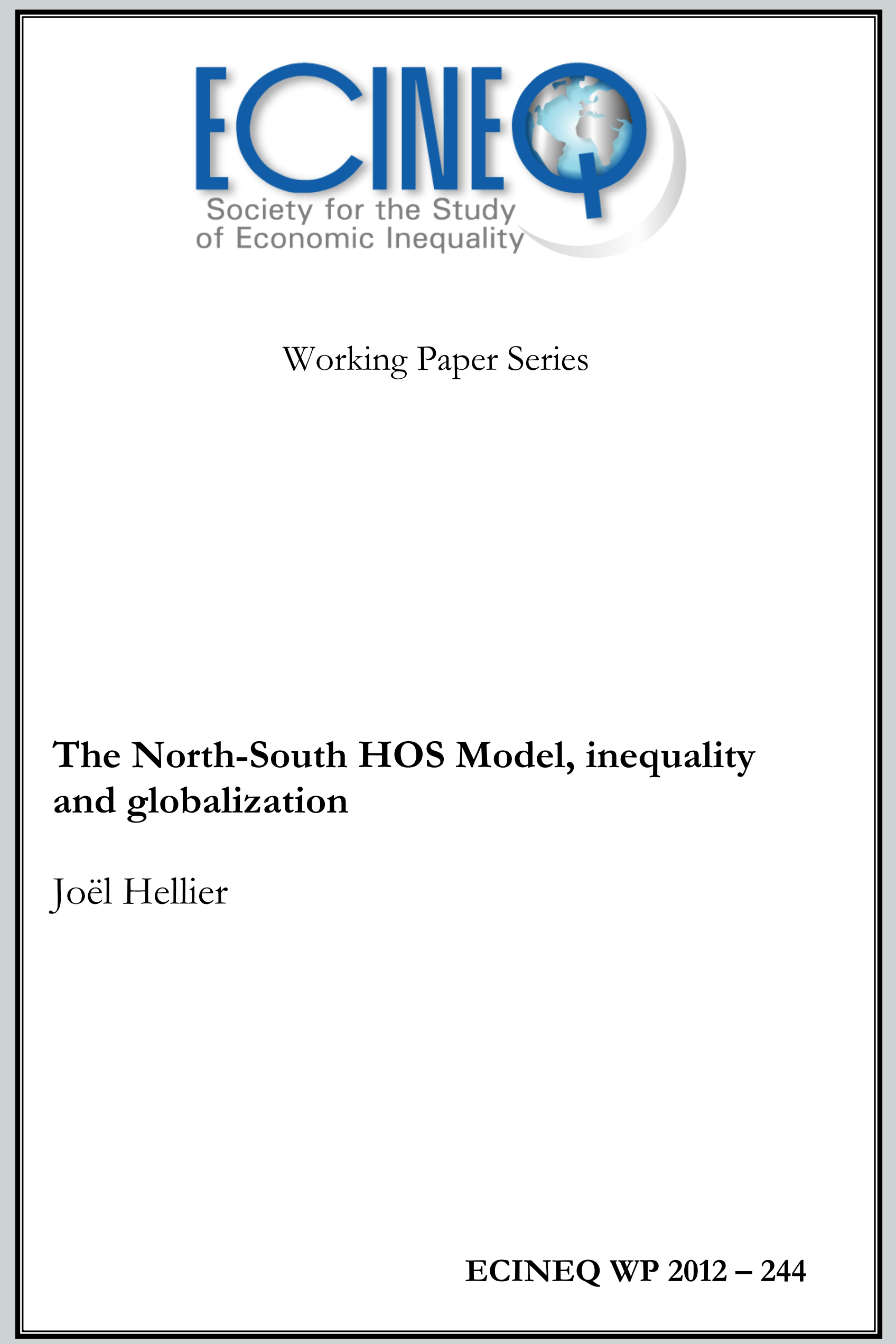




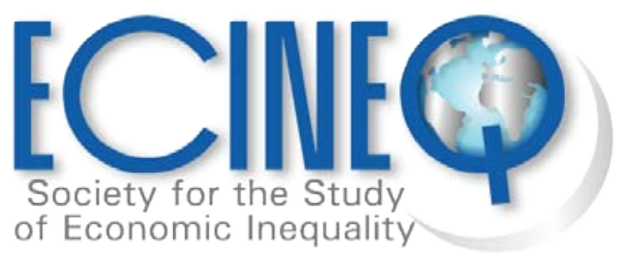

ECINEQ 2012 - 244

January 2012

www.ecineq.org

\title{
The North-South HOS Model, inequality and globalization
}

\author{
Joël Hellier ${ }^{\dagger}$ \\ EQUIPPE, University of Lille 1, and LEMNA, University of Nantes
}

\begin{abstract}
The predictions from the traditional North-South HOS approach are at variance with the main characteristics of the Inequality-Globalization nexus. It is shown that by modifying this model and relaxing some of its most restrictive assumptions, it is possible to generate these characteristics. Four series of extensions are analysed: 1) divergent factor endowments between the North and the South and growing size of the South; 2) labour market rigidities resulting from a minimum wage or from the fair wage hypothesis; 3 ) the introduction of technological differences between countries, of technological transfers, of technological catching up and of technological biases; 4) the inserting of production segmentation and international outsourcing. Further possible extensions are also discussed. The resulting augmented North-South HOS approach provides suitable modelling of the Inequality-Globalization nexus.
\end{abstract}

Keywords: Globalisation; H-O-S; Inequality; North-South model.

JEL Classification: D33; E24; F16; J31.

\footnotetext{
* I wish to thank the French Agence Nationale de la Recherche (ANR) for its financial support.

t Contact details: joel.hellier@wanadoo.fr
} 


\section{Introduction}

Three main explanations have been given to the increase in inequality observed in advanced countries (the North) in the last thirty years: institutional changes, skill biased technological change, and globalization.

Globalization impacts on inequality in the North through the competition from emerging countries (the South). The South being highly endowed with low skilled labour, North-South openness entails an increase in the skill premium (ratio of the wage of skilled workers on the wage of unskilled workers) in the North, i.e., a rise in inequality. This is based on the international specialisation of the North in skill-intensive goods and the South in unskilledintensive ones. In this story, inequality results from the trade-driven move in specialisation with different endowments of skilled and unskilled labour in the North and in the South. The usual theoretical framework to portray such an explanation is the $2 \times 2 \times 2$ North-South Heckscher-Ohlin-Samuelson (henceforth NS-HOS) model in which the two factors are skilled and unskilled labour.

However, if the NS-HOS framework provides a modelling of the increase in inequality in the North that derives from North-South openness, most of the observed developments are at variance with the model predictions. These contradictions comprise the changes in the relative price of goods and in skill intensities in the North, in inequality in the South, and the tendency towards factor price equalisation at the world level (see the full list in Section 3). These contradictions can lead to three attitudes concerning the relationship between the HOS model and inequality.

The first attitude consists in diagnosing a negligible impact of globalization (North-South openness) upon the changes in inequality. If the NS-HOS framework is well tailored to model North-South trade (NST), and if most of its predictions are not in line with observed facts, then NST is not a major explanation for the changes in inequality. This position was in a large majority amongst economists until the late 90s (Chusseau et al., 2008, for a survey). The minor impact of globalization upon inequality was essentially explained by the small size of the South (Krugman and Lawrence, 1993; Krugman 1995). However, such an argument is no longer valid given the critical increase in the weight of emerging countries in world trade and production since the mid-nineties (Krugman, 2008). With the advent of China and India, most of the HOS prediction should be verified if the HOS model provides a reliable picture of the main mechanisms of North-South openness.

A second attitude consists in diagnosing the inability of the HOS model to capture the key characteristics of globalisation and NST because of its restrictive assumptions (Desjonqueres et al., 1999). Several shortfalls in the traditional HOS framework have been put forward such as (i) its static nature, (ii) identical technologies in both the North and the South, (iii) the lack of segmentation in production, which impedes the modelling of international outsourcing, (iv) the need to account for rigidities in labour markets etc. Finally, North-South openness and globalization may well act upon inequality through channels other than specialisation in trade, e.g. through technology and capital transfers, differences in property rights enforcement, migrations etc. Despite the accuracy of these critiques, the impact of the relocation to the South of an increasing share of unskilled-intensive sectors has become a major characteristic of the globalisation process, and this cannot be underestimated by economic analysis.

A third attitude consists in accepting the HOS framework as a starting point and to significantly amend it so as to model certain key mechanisms that its traditional version cannot portray because of over restrictive assumptions. This conception is based on the fact that the main advantage of the South in world trade still rests upon the possession of a large and relatively cheap unskilled manpower. Since multinational firms can easily produce in the South, both capital and technology can be considered as mobile whereas North-South 
migrations of skilled and unskilled labour remain costly and subject to high institutional restrictions. Such facts favor the adoption of the NS-HOS framework. However, this model must be substantially amended so as to account for the above critiques and to enable its predictions to coincide with the main observed developments.

The aim of this chapter is to show how, by relaxing certain restrictive assumptions and adding new hypotheses, the extension of the traditional NS-HOS framework makes it possible to generate most of the characteristics of the globalization-inequality nexus.

Section 2 lists stylised facts on globalisation and inequality over the last thirty years. The traditional NS-HOS model is built in Section 3 and its mains predictions are compared with the stylised facts, which demonstrates inadequacy between the model and the observed developments. The subsequent five sections are devoted to several possible extensions. A concluding section summarises the correspondences between the examined extensions and the stylised facts.

\section{Globalization and inequality: Stylised facts}

We start from the following stylised facts concerning the globalization process and the dynamics of inequality since the eighties:

1. A critical increase in the weight of emerging countries (the South) in the production and exports of manufacturing, and thereby a significant decrease in the weight of advanced countries (the North).

2. The South is specialized in the production and exports of unskilled-intensive goods and the North in skill-intensive goods, and the skill level of the working population is substantially higher in the North compared to the South.

3. The development of international outsourcing, i.e., a situation in which the different segments of production processes are located in different countries. In particular, the skill intensive segments remain in the North whereas the unskilled intensive segments are relocated to the South.

4. In terms of production and specialisation, the South did not produce skill-intensive goods at the outset of globalization and the North stopped producing unskilled intensive tradable goods from late 2000.

5. An increase in the skill intensity (ratio of the utilisation of skilled on the utilisation of unskilled labour in production) in almost all industries in both the North and the South.

6. A critical increase in foreign direct investments (FDIs) from the North to the South.

7. In most northern countries, an increase in unemployment compared to the preglobalization period, and particularly in unemployment of unskilled workers.

8. A significant increase in the skill level of the working population in all northern countries over the last forty years.

9. The wage gap between the North and the South remains substantial for unskilled workers as well as for skilled workers.

10. No tendency towards international skill premia equalisation, neither between northern countries, nor between southern countries, nor between the North and the South. 
11. Inequality (the skill premium) remains higher in southern countries than in northern countries.

12. An increase in the skill premium (inequality) in almost all northern countries over the last thirty years, with albeit substantial differences across countries.

13. Miscellaneous variations in the skill premia and inequality in southern countries (see Chapter 2). More precisely, inequality had decreased in East Asia from the early 80s to the mid-90s, but it has increased since this period. Inequality seems to have increased in most of the Latin American countries, as well as in China and India since the early 90s, but it has regressed in China and certain Latin American countries since the mid-2000s. Nevertheless, the general diagnosis is that of an increase in inequality.

14. No increase in the prices of the skill-intensive goods in relation to those of unskilled intensive goods in the North.

The first eight stylised facts cover the globalization characteristics in terms of production, skill, trade and international specialisation. The last six facts deal with wages, inequality and prices. Since our concern is the income gap between skilled and unskilled workers, inequality is measured by the skill premium, i.e., the ratio of skilled workers' wage on unskilled workers' wage.

\section{The traditional NS- HOS model and its shortfalls}

The traditional North-South HOS model is firstly constructed and its main predictions underlined. We subsequently compare these predictions with the observed (stylised) facts exposed in Section 2.

\subsection{The North-South HOS model}

We construct an HOS model with two factors, skilled labour $H$ and less skilled labour $L$, two goods $h$ and $l$, the production of $h$ being $H$-intensive and that of $l$ being $L$-intensive, and two countries/areas, the North $(N)$ and the South $(S)$. Values at the world level are depicted by the subscript $W$. As usual in HOS models, factor endowments $\bar{L}_{i}$ and $\bar{H}_{i}, i=N, S$, are given and factors are internationally immobile. The North is relatively better endowed with skilled labour and the South with unskilled labour. Consequently the unskilled labour relative endowments $\bar{\lambda}_{i}=\bar{L}_{i} / \bar{H}_{i}$, are such that $\bar{\lambda}_{S}>\bar{\lambda}_{N}$. All the usual HOS assumptions concerning pure competition, identical technology and identical demand functions in both countries, no transport cost etc., are maintained.

For the sake of simplicity, we assume log-linear utility and production functions. In both countries and at the world level, the (instantaneous) utility function is such that good $l$ accounts for the proportion $\beta$ of total income and expenditure, and good $h$ for the proportion $(1-\beta)$. The production functions are Cobb-Douglas: $Y_{j}=A_{j} L_{j}{ }^{\alpha_{j}} H_{j}{ }^{\alpha_{j}}, j=h, l$, with $\alpha_{l}>\alpha_{h}$ because of the assumed difference in skill intensity between sectors.

Resolving this model provides the full employment equilibrium values of the skill premium $\omega=w_{H} / w_{L}$ and of the relative price $p_{h} / p_{l}$, (i) for each country $i$ being in autarky $(i=N, S)$ and (ii) at the world level $(i=W)$ in free trade (see Appendix): 


$$
\begin{aligned}
& \hat{\omega}_{i}=\frac{1-\alpha}{\alpha} \times \frac{\bar{L}_{i}}{\bar{H}_{i}}=\frac{1-\alpha}{\alpha} \bar{\lambda}_{i} \\
& \frac{p_{h i}}{p_{l i}}=\frac{A_{l}}{A_{h}} \frac{\alpha_{l}^{\alpha_{l}}}{\alpha_{h}^{\alpha_{h}}} \frac{\left(1-\alpha_{l}\right)^{1-\alpha_{l}}}{\left(1-\alpha_{h}\right)^{1-\alpha_{h}}} \hat{\omega}_{i}^{\alpha_{l}-\alpha_{h}}
\end{aligned}
$$

with $\alpha=\beta \alpha_{l}+(1-\beta) \alpha_{h}, \bar{L}_{W}=\bar{L}_{N}+\bar{L}_{S}, \bar{H}_{W}=\bar{H}_{N}+\bar{H}_{S}$ and $\bar{\lambda}_{i}=\bar{L}_{i} / \bar{H}_{i}, i=N, S, W$.

Since $\bar{\lambda}_{S}>\bar{\lambda}_{N}$, the world relative endowment $\bar{\lambda}_{W}=\bar{L}_{W} / \bar{H}_{W}$ is such that $\bar{\lambda}_{S}>\bar{\lambda}_{W}>\bar{\lambda}_{N}$ and the skill premia hierarchy is:

$$
\hat{\omega}_{S}>\hat{\omega}_{W}>\hat{\omega}_{N}
$$

Relations (1)-(3) establish the following results that are usual predictions of the HOS model:

1. The existence of a unique skill premium at the world level (relation (1) for $i=W$ ) combined with identical technologies in both countries result in international factor price equalisation (FPE) in the case of free trade between the North and the South. It must however be remembered that FPE is conditioned by the location of both countries inside the diversification cone (McKenzie, 1955, Chipman, 1969; see the analysis in Section 4).

2. The differences in factor relative endowments combined with identical demand function for goods entails a specialisation of the North in the exports of $h$ and the South in the exports of $l$ for identical factor prices in both countries.

3. The Stolper-Samuelson theorem directly stems from Relation (2): an increase in one good's relative price induces an increase in the relative return to the factor in which this good is intensive.

4. Relation (3) shows that North-South openness leads to an increase in the Skill premium in North $\left(\hat{\omega}_{W}>\hat{\omega}_{N}\right)$ and a decrease in the South $\left(\hat{\omega}_{S}>\hat{\omega}_{W}\right)$, i.e., a rise in inequality in the North and a reduction of inequality in the South.

5. Openness decreases skill intensities in the North and increases them in the South in both sectors $h$ and $l$. This directly stems from the increase (decrease) in the skill premium in the North (South).

Finally note that in the situation of free trade between the North and the South, the law of one price on the markets for goods shows that both countries must share the same skill premium $\hat{\omega}_{W}$ if they both produce both goods (Relation 2).

\subsection{Stylised facts against the NS-HOS model}

Table 1 compares the stylised facts exposed in Section 2 with the results of the NS-HOS model determined above. Table 2 compares the predictions of the NS-HOS model with observed developments. 
Table 1. Stylised facts against the NS-HOS model

\begin{tabular}{|l|c|}
$\qquad$ Stylised facts & $\begin{array}{c}\text { Suitability with the } \\
\text { NS-HOS model }\end{array}$ \\
\hline $\begin{array}{l}\text { 1. The South is specialized in the production and export of unskilled } \\
\text { intensive goods and the North in skill-intensive goods }\end{array}$ & yes \\
\hline 2. Development of international outsourcing & irrelevant \\
\hline $\begin{array}{l}\text { 3. An increase in the skill intensity in all industries in both the North and } \\
\text { the South. }\end{array}$ & no \\
\hline 4. A critical increase in FDIs from the North to the South & irrelevant \\
\hline 5. An increase in unemployment of unskilled workers in the North & no \\
\hline $\begin{array}{l}\text { 6. The wage gap between the North and the South remains substantial for } \\
\text { unskilled workers as well as for skilled workers }\end{array}$ & no \\
\hline 7. Increase in the skill premium (inequality) in the North & yes \\
\hline 8. The skill premium remains higher in the South than in the North & no \\
\hline 9. No tendency towards international skill premia equalisation & no \\
\hline 10. No decrease in the skill premium in the South & no \\
\hline $\begin{array}{l}\text { 11. No increase in the prices of skill-intensive goods in relation to unskilled } \\
\text { intensive ones in the North }\end{array}$ & no \\
\hline
\end{tabular}

Table 2. The NS-HOS predictions against stylised facts

\begin{tabular}{|l|c|}
\multicolumn{1}{|c|}{ NS-HOS predictions } & $\begin{array}{c}\text { Suitability with } \\
\text { stylised facts }\end{array}$ \\
\hline $\begin{array}{l}\text { 1. The South is specialized in the production and export of unskilled } \\
\text { intensive goods and the North in skill-intensive goods }\end{array}$ & yes \\
\hline 3. An decrease in the skill intensity in all industries in the North & no \\
\hline 4. An increase in the skill intensities in the South & yes \\
\hline 5. Full employment in both countries & no \\
\hline 6. Tendency to factor price and skill premia equalisation & no \\
\hline 7. Increase in the skill premium (inequality) in the North & yes \\
\hline 8. Decrease in the skill premium in the South & no \\
\hline 9. Increase in the relative price of skilled-intensive goods in the North & no \\
\hline
\end{tabular}

When compared to stylised fact, the NS-HOS results can be either in agreement ('yes' in Table 1), or in contradiction ('no'), or irrelevant if the model cannot predict anything about it because its structure is inadequate. The only two developments consistent with the NS-HOS results are the specialisation patterns ( $h$ in the North and $l$ in the South) and the increase in the skill premium (inequality) in the North. Seven of the listed eleven facts are in contradiction with the model, and the model is irrelevant for two observed facts. In addition, only three NSHOS predictions are confirmed by the observed developments, whereas five are clearly denied. As a consequence, the traditional North-South HOS model appears to be largely unsuitable for explaining the main characteristics of globalization on the one hand and of the globalization-inequality nexus on the other hand. This is essentially due to its restrictive assumptions. In particular:

1. Assuming given endowments cannot account for the increase in the size of the South that derives from the fact that new southern regions and countries have been continuously joining the globalized economy for the last thirty years. This increase in the size of the South will be added to the analysis as an exogenous dynamics.

2. By assuming factor price equalisation, we have implicitly assumed that both the North and the South were inside the diversification cone. The effects of waiving this assumption are analysed in Section 4. 
3. The assumption of pure competition on the labour markets results in full employment in both the North and the South. Section 5 is centred on the release of this assumption by introducing (i) a minimum wage in the North, and (ii) an efficiency wage hypothesis.

4. The NS-HOS model assumes identical technologies in both countries. Section 6 releases this assumption by introducing technological differences between the North and the South.

5. The traditional HOS framework cannot account for international outsourcing because it disregards segmentation in production. This is incorporated into the analysis in Section 7.

\section{The NS-HOS model outside the diversification cone}

A first extension to the NS-HOS model consists in considering the cases in which both countries are not inside the diversification cone corresponding to FPE (D-cone hereafter). This assumption is rather appropriate because it corresponds to a situation where factor endowments significantly differ between countries, which is clearly the case between northern and southern countries in terms of skill attainment. By combining the growing size of the South and significant differences in skill endowments that prevent both countries to belong simultaneously to the D-cone, three stages of globalization are generated that differ in terms of specialisation and inequality in each country.

\subsection{The Diversification cone}

A well-known condition for the HOS general equilibrium to generate factor price equalisation is that both countries are inside the diversification cone corresponding to FPE.

In the quadrant $(H, L)$, the $\mathrm{D}$-cone is delimited by the two lines $L=\frac{\alpha_{l}}{1-\alpha_{l}} \hat{\omega}_{W} H$ and $L=\frac{\alpha_{h}}{1-\alpha_{h}} \hat{\omega}_{W} H$ that respectively correspond to all the couples $(H, L)$ consistent with the production of $l$ and to all the couples $(H, L)$ consistent with the production of $h$ for the world equilibrium skill premium $\hat{\omega}_{W}$ corresponding to factor price equalization (Figure 1).

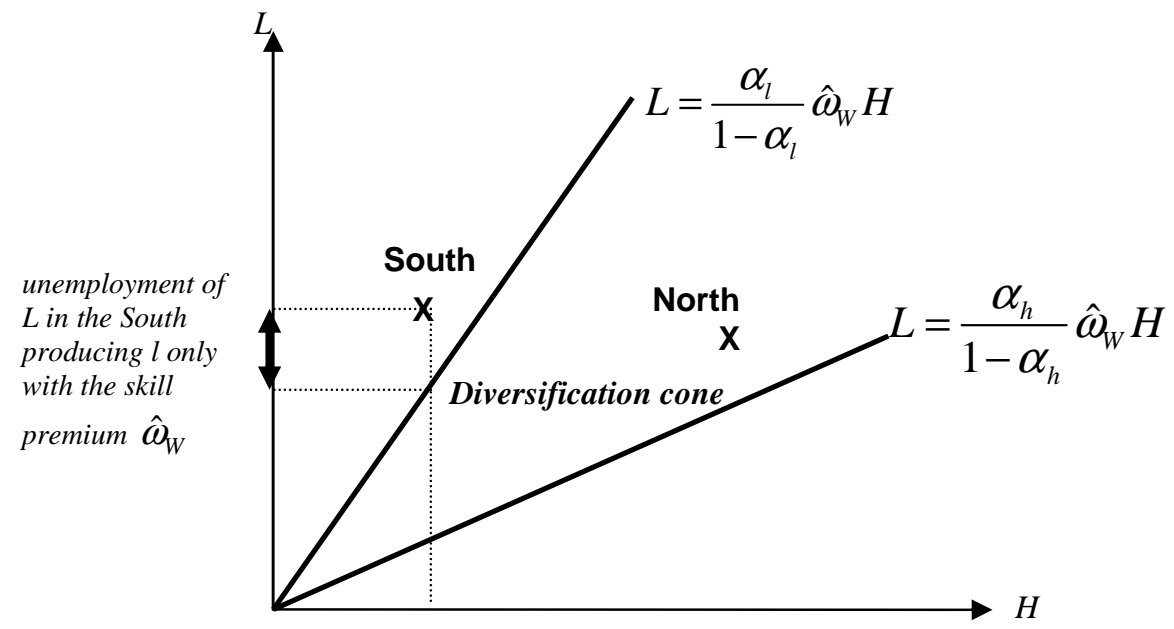

Figure 1. The diversification cone 
If at least one of the two countries is outside the D-cone, this country cannot attain full employment with the world skill premium $\hat{\omega}_{W}$. In Figure 1, the South suffers unemployment of the unskilled for the skill premium $\hat{\omega}_{W}$ even when producing good $l$ only. Then, because of competitive labour markets, the skill premium of the South increases above $\hat{\omega}_{W}$ and FPE does not occur. In this case, (i) the South has a higher skill premium than both that of the North and that corresponding to FPE, and (ii) the South produces good $l$ only and the North both goods at the free trade equilibrium.

Finally note that a situation in which one at least of the countries is not inside the D-cone corresponds to significant differences in factor relative endowments between the two countries.

\subsection{Globalization}

Globalization is defined by two features:

1) An increase in the size of the South, this size being insignificant at the beginning of the globalization process, whereas the size of the North becomes small compared to the South at its conclusion. This aims at portraying the fact that new southern countries and regions continuously join the globalized economy and that this comes to an end when the whole world is globalized. The increase in the size of the South results (i) in the world factor endowments $\left(\bar{H}_{W}, \bar{L}_{W}\right)$ and the relative endowment $\bar{\lambda}_{W}$ being those of the North at the outset of globalisation, and (ii) in the world factor endowments and relative endowment tending towards those of the South as the size of the South increases (Figure 2a). In addition, since the world skill premium corresponding to FPE is $\hat{\omega}_{W}=\frac{1-\alpha}{\alpha} \bar{\lambda}_{W}$ and the countries' skill premia in autarky $\hat{\omega}_{i}=\frac{1-\alpha}{\alpha} \bar{\lambda}_{i}, i=N, S$, the globalization process corresponds to $\hat{\omega}_{W}$ moving from $\hat{\omega}_{N}$ towards $\hat{\omega}_{S}$ as shown in Figure $2 b$.

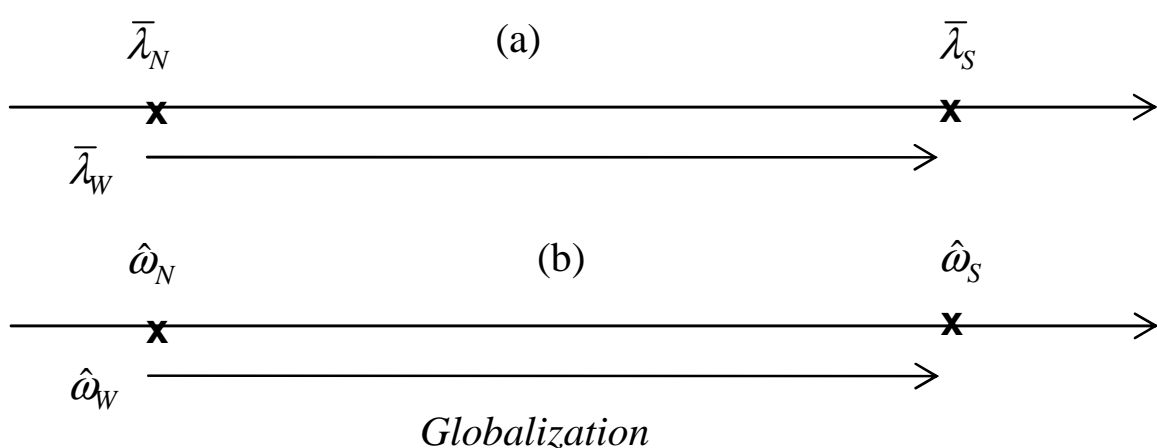

Figure 2. World relative endowment and skill premium throughout globalization

2) A large difference in the countries' factor endowments that results in a relative endowment of unskilled labour $\bar{\lambda}_{i}=\bar{L}_{i} / \bar{H}_{i}, i=N, S$, that is substantially higher in the South than in the North. This depicts the large differences in skill endowments observed between southern and northern countries. We shall suppose that this difference in relative endowments is large enough to place the South outside the D-cone at the beginning of globalization, and the North outside the D-cone at the conclusion of globalization. 
All the other assumptions of the traditional NS-HOS model are preserved, particularly the constancy of the countries' relative endowments $\bar{\lambda}_{i}, i=N, S$. This depicts the fact that the southern newcomers have a low skill endowment, thereby maintaining $\bar{\lambda}_{S}$ at a high level ${ }^{1}$. It is however clear that both $\bar{\lambda}_{N}$ and $\bar{\lambda}_{S}$ are growing with time. This is discussed in Section 8 .

By combining the second and first features, and given that the D-cone is located inbetween lines $L=\frac{\alpha_{h}}{1-\alpha_{h}} \hat{\omega}_{W} H$ and $L=\frac{\alpha_{l}}{1-\alpha_{l}} \hat{\omega}_{W} H$, it is possible to represent the globalization process in the quadrant $(H, L)$ as depicted in Figure 3.

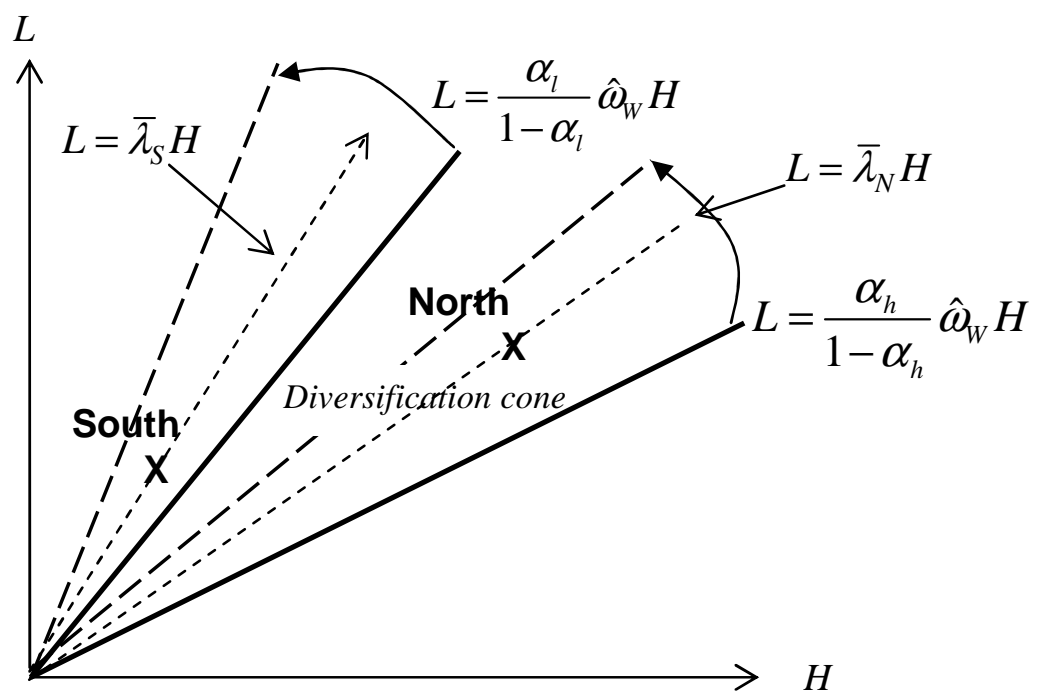

Figure 3. Globalization, the diversification cone and factor endowments

Firstly, as $\hat{\omega}_{W}$ increases, globalisation leads to a rotation to the left of the D-cone. At the beginning of globalization, the North is inside the cone and the South outside whereas the South is inside the cone and the North outside at the conclusion of the globalisation process.

Secondly, the South rises in size with a constant relative endowment $\bar{\lambda}_{S}$, which can be depicted by an upward move of the South endowments $\left(\bar{H}_{S}, \bar{L}_{S}\right)$ along the line $L=\bar{\lambda}_{S} H$.

Thirdly, the northern endowment $\left(\bar{H}_{N}, \bar{L}_{N}\right)$ remains constant and it is situated on the line $L=\bar{\lambda}_{N} H$.

Finally, the D-cone corresponds to the set of endowments in-between lines $L=\frac{\alpha_{h}}{1-\alpha_{h}} \hat{\omega}_{N} H$ and $L=\frac{\alpha_{l}}{1-\alpha_{l}} \hat{\omega}_{N} H$ at the outset of globalization, and it tends towards the set in-between lines $L=\frac{\alpha_{h}}{1-\alpha_{h}} \hat{\omega}_{S} H$ and $L=\frac{\alpha_{l}}{1-\alpha_{l}} \hat{\omega}_{S} H$ with the growing size of the South.

\footnotetext{
We can also consider that the first wave of NICs (Hong Kong, Korea, Singapore and Taiwan) no longer belongs to the South.
} 


\section{The three stages of globalization, specialisation and inequality}

It is now possible to distinguish three stages in the globalization process. At the beginning of globalisation, the North is inside the D-cone and the South outside. This corresponds to the South being small (Figure 4a). As the D-cone rotates to the left with the increasing size of the South, this first stage comes to an end. This can take place by 2 means: either the South enters the D-cone as the North is still inside and both countries are then inside the cone (Figure 4b1), or the North quits the cone when the South is still outside and they are then both outside the cone (Figure 4b-2). These are the two cases corresponding to the South being mediumsized. Finally, from a certain time, the growing size of the South brings it inside the D-cone and brings the North outside. This corresponds to the South being large (Figure 4c).

Henceforth, we denote $\tilde{\omega}_{i}$ the open economy equilibrium skill premium in country $i=N, S$ when this value differs from the skill premium $\hat{\omega}_{W}$ corresponding to FPE.

\section{(a) Small South}

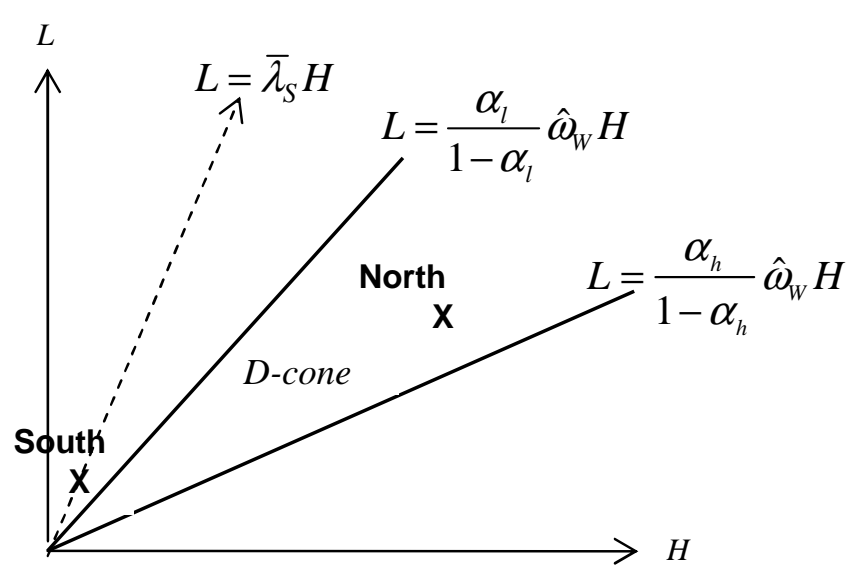

(b) Medium-sized South
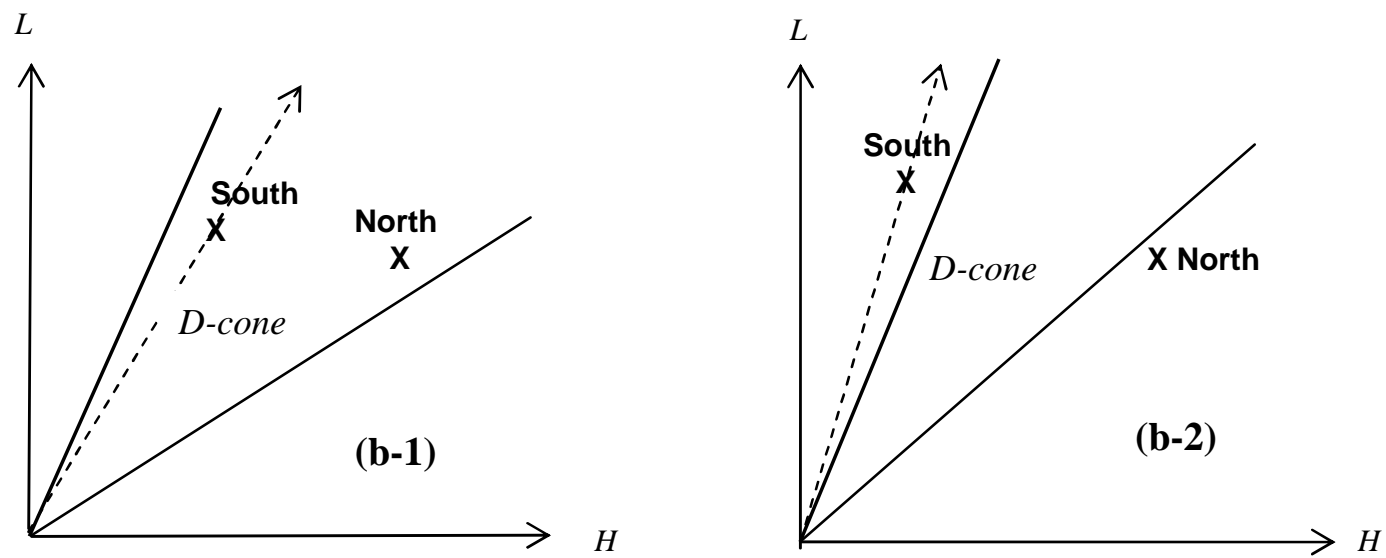

(c) Large South 


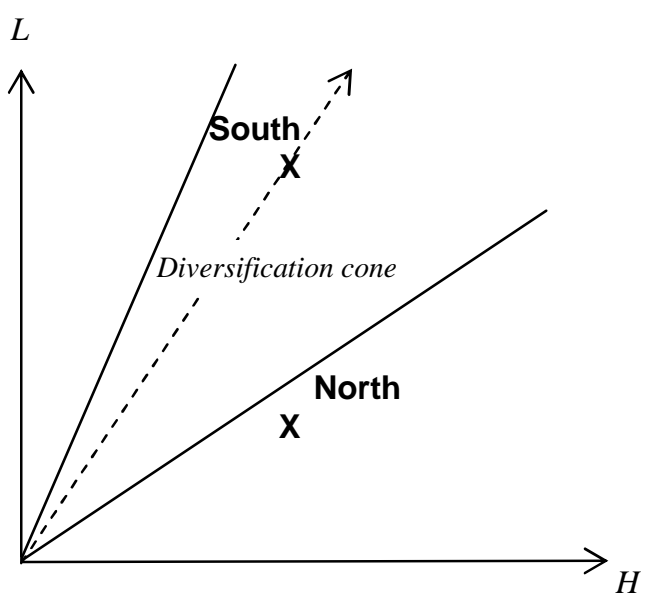

Figures 4. The three stages of globalization

\section{First stage: Small South}

As long as the South is small enough to remain outside the D-cone and the North stands inside (Figure $4 \mathrm{a}$ ), the North produces both goods and the South good $l$ only. The skill premium of the South is $\tilde{\omega}_{S}=\frac{1-\alpha_{l}}{\alpha_{l}} \bar{\lambda}_{S}$ (since it produces $l$ only) and remains constant provided that the South produces $l$ only, i.e., throughout the first stage of globalization. In addition, $\tilde{\omega}_{S}<\hat{\omega}_{S}$ because $\alpha_{l}>\alpha$. Consequently, inequality in the South is lower after openness than in autarky, but higher than both the inequality in the North and the inequality corresponding to FPE. In the North, inequality continuously grows as the South corners an increasing share of the production of $l$ because of its growing size.

\section{Second stage: Medium-sized South}

The increasing size of the South producess a rotation of the D-cone to the left. From a certain time, this rotation causes (i) either the South to enter the D-cone as the North is still inside, (ii) or the North to quit the cone as the South is still outside.

When the South enters the D-cone as the North is still inside (Figure 4b-1), both countries are inside the cone as long as the North remains inside, i.e., throughout the second stage. Then, factor price equalisation occurs and both countries share the same skill premium $\hat{\omega}_{W}=\frac{1-\alpha}{\alpha} \bar{\lambda}_{W}$. The growing size of the South causes an increase in $\bar{\lambda}_{W}$ and in $\hat{\omega}_{W}$, i.e. rising inequality, throughout the second stage in both the North and the South.

When the North quits the D-cone before the South enters the cone (Figure 4b-2), both countries are outside the D-cone during the second stage. This typically corresponds to each country producing one good only, $h$ in the North and $l$ in the South. As the North produces $h$ only, its skill premium remains constant at the value $\tilde{\omega}_{N}=\frac{1-\alpha_{h}}{\alpha_{h}} \bar{\lambda}_{N}$, i.e., the highest possible full employment skill premium of the North. As the South produces $l$ only, its skill premium remains at value $\tilde{\omega}_{S}=\frac{1-\alpha_{l}}{\alpha_{l}} \bar{\lambda}_{S}$ as in the first stage. 


\section{Third stage: Large South}

The North is outside the D-cone and produces good $h$ only whereas the South is inside the cone and produces both goods (Figure 4c). Thus, the skill premium and inequality remain constant and high in the North. Because of its growing size, the South must increase the share of good $h$ in its production, which raises the demand for skilled workers and hence the skill premium and inequality in the South.

\section{More than one northern country}

If we assume more than one northern country with different relative endowments between countries, the model generates different skill premia in these countries once the North produces good $h$ only. The higher a northern country's skill endowment, the lower its skill premium and inequality (northern country $n$ with a relative endowment $\bar{\lambda}_{n}$ has the skill premium $\tilde{\omega}_{n}=\frac{1-\alpha_{h}}{\alpha_{h}} \bar{\lambda}_{n}$ ).

Table 3 summarises the main characteristics of each stage of globalisation in terms of sectoral specialisation and inequality in both the North and the South.

Table 3. Main characteristics of the three stages of globalization

\begin{tabular}{|c|l|l|}
\hline Stages & \multicolumn{1}{|c|}{ North } & \multicolumn{1}{|c|}{ South } \\
\hline $\begin{array}{c}\text { Stage 1 } \\
\text { Small South }\end{array}$ & $\begin{array}{l}\text { - Production of both goods. } \\
\text { - Continuous increase in inequality } \\
\text { from the autarkic level. }\end{array}$ & $\begin{array}{l}\text { - Production of good } l \text { only; } \\
\text { - Constant inequality, significantly } \\
\text { lower than in autarky; }\end{array}$ \\
\hline Stage 2 & $\begin{array}{l}\text { 1) Both countries produce both goods } \\
\text { - FPE with continuous increase in }\end{array}$ & $\begin{array}{l}\text { 1) Both countries produce both goods } \\
\text { - FPE with continuous increase in } \\
\text { inequality }\end{array}$ \\
Sodium-sized & $\begin{array}{l}\text { inequality } \\
\text { 2) Each country produces 1 good only } \\
\text { - Constant inequality, high compared } \\
\text { to autarky. }\end{array}$ & $\begin{array}{l}\text { 2) Each country produces 1 good only } \\
\text { - Constant inequality, low compared } \\
\text { to autarky }\end{array}$ \\
\hline Stage 3 & $\begin{array}{l}\text { - Production of good h only; } \\
\text { - Constant inequality, high compared } \\
\text { to autarky. }\end{array}$ & $\begin{array}{l}\text { - Production of both goods. } \\
\text { - Continuous increase in inequality } \\
\text { towards its autarkic level. }\end{array}$ \\
\hline
\end{tabular}

We have assumed large differences in factor endowments that prevent the simultaneous location of both countries inside the $\mathrm{D}$-cone. This clearly produces new predictions that differ from the usual NS-HOS results and are consistent with certain stylise facts. In particular:

1. No factor price and no skill premium equalisation, with inequality (the skill premium) being higher in the South than in the North, which corresponds to stylised facts 9, 10 and 11.

2. No production of the $H$-intensive good in the South at the first stage(s) of the globalisation process, and no production of $L$-intensive goods in the North at the latter stage(s) (stylised fact 4)

However, certain key observed developments remain unexplained, such as the increase in unemployment in the North, the fact that both skilled and unskilled workers are better paid in the North than in the South, the rise in inequality in the South etc. 


\section{Wage rigidity}

The HOS model assumes perfect competition in labour markets, which in turn ensures full employment in both countries even when these are not both inside the D-cone. To generate unemployment in the North, it is thus necessary to release this assumption. In the economic literature, this has been carried out by several means (minimum wage, search and matching models, bargaining, efficiency wages etc.). The introduction of a minimum wage into a HOS model was initiated by Brecher (1974) and extended by Davis (1998). Models with comparative advantages and frictional unemployment are proposed by Davidson and al. (1988, 1999). Felbermayr et al. (2011) insert search frictions into a model with increasing returns to scale and Helpman \& Itskhoki (2010) introduce search and matching into a model that combines comparative advantage and increasing returns to scale. Finally, a number of works (Agell \& Lundborg, 1995; Albert \& Merckl, 2001; Kreickemeier \& Nelson, 2006; Kreickemeier, 2008; Egger \& Kreickemeier, 2009) have introduced efficiency wages into HOS and increasing returns models. We insist here on two types of approach that have received a particular attention, i.e., the insertion of a minimum wage and of efficiency wages into HOS models.

\subsection{Minimum wage in the HOS model: the Davis approach and extensions}

\section{Davis' model}

Davis (1998) introduces a minimum wage into a North-North HOS model so as to explain the difference in unemployment between Europe and the US. The setting of a minimum wage by Europe is modelled by the enforcement of a skill premium $\bar{\omega}$ that is lower than that corresponding to the world equilibrium with purely competitive labour markets: $\bar{\omega}<\hat{\omega}_{W}$. In contrast, the US leaves market forces free to work. This leads to FPE at the world level, the US 'adopting' Europe's minimum wage and skill premium. This result directly derives from a traditional market clearing mechanism. As long as the skill premium is lower in Europe than in the US, the skill-intensive good $h$ is cheaper, and the unskilled-intensive $l$ more costly, when produced in Europe than in the US. This displaces the demand for $h$ towards Europe, and that for $l$ towards the US. The related increase in the demand for unskilled labour in the US causes a decrease in this country's skill premium until it reaches the European level $\bar{\omega}$. The move of the US skill premium down to $\bar{\omega}$ directly stems from the natural change of specialisation due to differences in relative prices and wages. This mechanism works without creating unemployment in the US since there is no impediment to market clearing there. Consequently, the world unemployment of unskilled workers due to the adoption by both countries of a skill premium lower than its market clearing value is totally located in Europe. Finally, the introduction of emerging countries into the initial North-North framework increases unemployment in Europe only, the US being preserved from both unemployment and inequality by the European minimum wage.

The same rationale with the same results can be applied to the NS-HOS model in which the North enforces a minimum wage whereas the South maintains competitive labour markets. In this case, the South benefits from the North minimum wage and the world unemployment created by this is fully located in the North.

The Davis model is questionable for several reasons. Firstly, its main result is at variance with observed facts since growing unemployment in Europe has coincided with growing inequality in the US. Secondly, the fact that the new competition from emerging countries bears no impact upon the US is conditioned by both northern countries being in the diversification cone. Suppose that, because of the minimum wage, Europe produces good $h$ 
(skill-intensive) only whereas the US produces both goods. Then, the competition from emerging countries has no impact upon Europe whereas it reduces the production of good $l$ (unskilled labour intensive) by the US, resulting in growing inequality (skill premium) in this country (Oslington, 2002). This is typically more consistent with the observed developments in inequality. However, it rests upon a specialisation that is more skill intensive in Europe than in the US, which does not reflect reality.

Finally, when applied to the NS-HOS model, the Davis mechanism supposes that both the North and the South belong to the cone corresponding to the skill premium $\bar{\omega}$ (henceforth $\bar{\omega}$ cone), i.e., the set of points in-between lines $L=\frac{\alpha_{h}}{1-\alpha_{h}} \bar{\omega} H$ and $L=\frac{\alpha_{l}}{1-\alpha_{l}} \bar{\omega} H$ (Figure 5). This is all the more unlikely given that the $\bar{\omega}$-cone is below the D-cone, which signifies that the South can be inside the D-cone and outside the $\bar{\omega}$-cone (as in Figure 5).

Minimum wage in the NS-HOS model with the South outside the D-cone

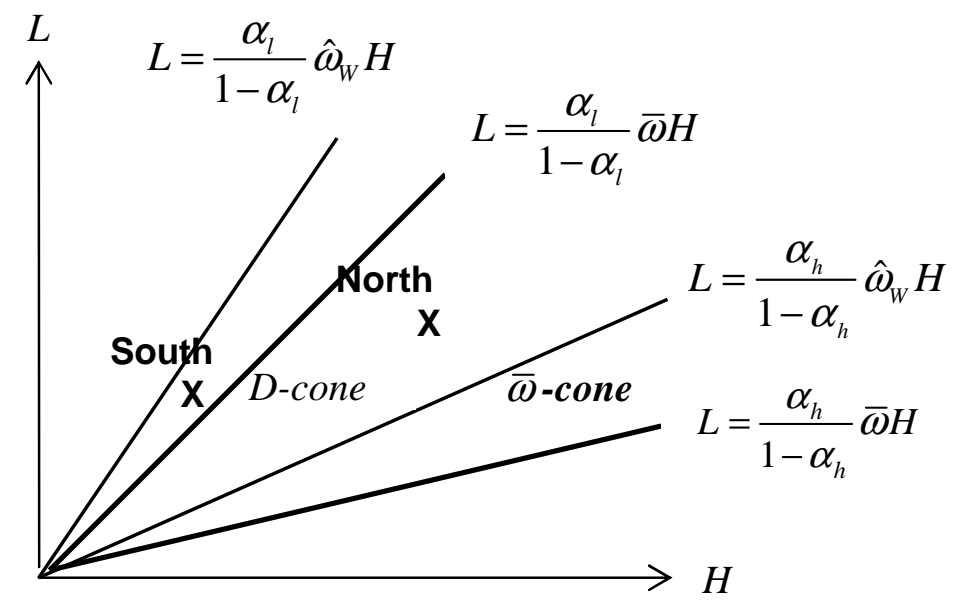

Figure 5. D-cone and $\bar{\omega}$-cone

If the South is outside the D-cone before the setting of a minimum wage by the North, then it is outside the $\bar{\omega}$-cone. In this case, the South produces the sole good $l$ before and after the setting of the North's minimum wage, and its skill premium remains unchanged. In the North, the setting of the minimum wage creates unemployment.

If the South is inside the D-cone before this setting of the minimum wage and outside the $\bar{\omega}$-cone (Figure 5), then the South moves from a situation where it produced both goods to a situation in which it produces good $l$ only, which lowers the southern skill premium. Consequently, the setting of a minimum wage in the North reduces inequality in the South. In the North, the rise in unemployment is intensified by the fact that the South only produces good $l$, which increases the share of $h$ in the North's production.

\subsection{Efficiency wages in the HOS approach}

The introduction of efficiency wages into HOS modelling was initiated by Agell and Lundborg (1995). A number of works have subsequently extended this type of approach (Albert \& Merckl, 2001; Kreickemeier \& Nelson, 2006; Kreickemeier, 2008; Egger \& Kreickemeier, 2009). Most of these works are based on the fair wage hypothesis, i.e., the fact 
that employees adjust their working effort by comparing their wage to a reference wage considered as fair.

In this section, the analysis confines itself to the introduction of the fair wage hypothesis within the North into the NS-HOS model developed in Section 3.

The production functions of the North are modified so as to account for the effort provided by workers. These functions are now $Y_{j}=A_{j}\left(E_{L j} \times L_{j}\right)^{\alpha_{j}}\left(E_{H j} \times H_{j}\right)^{1-\alpha_{j}}$, where $E_{k j}$ is the effort provided by workers of type $k, k=H, L$, in $j$-industry, $j=h, l$.

Let us assume that the worker's effort $E$ depends on the comparison between the worker's wage $w$ and a reference wage $w^{*}$ such that $E\left(w, w^{*}\right)=\min \left\{\eta\left(w, w^{*}\right), 1\right\}$, with (i) $\eta(\cdot)$ being continuous, twice derivable and monotonically increasing in $w$ and decreasing in $w^{*}$, and (ii) $\eta\left(w^{*}, w^{*}\right)=1$ (thus $\left.E(w)=1, w \geq w^{*}\right)$. Wage $w^{*}$ is considered as 'fair' by workers, i.e., they provide the maximum effort when they are paid at least $w^{*}$. We also assume that the reference wage $w^{*}$ is in-between the highest and the lowest wage in the economy. With homogenous skilled and unskilled labour, this results in $w_{L}<w^{*}<w_{H}$. As a consequence, skilled workers always provide the maximum effort 1 and the market for skilled labour is perfectly competitive.

As usual in efficiency wage models, the firms cannot control the workers' efforts but they know their effort function. Thus, firms maximise their profit $\pi=p Y-w_{L} L-w_{H} H$ subject to the technology $Y_{j}=A_{j}\left(E\left(w_{L, j}\right) \times L_{j}\right)^{\alpha_{j}}\left(H_{j}\right)^{1-\alpha_{j}}$ for industry $j=h$, $l$, and the effort function $E\left(w_{L j}\right)=\eta\left(w_{L j}\right)$. This maximisation programme generates the usual Solow condition $w_{L} \eta^{-1} \eta_{w_{L}}^{\prime}=1$, which determines a unique efficiency wage $w_{\text {eff }}$ that is the same in both sectors $^{2}$. If the efficiency wage is higher than the full employment wage $\hat{w}_{L}=\frac{\alpha}{1-\alpha} \frac{\bar{H}}{\bar{L}} w_{H}$, then this generates unemployment of the less skilled.

Let us suppose now that, before North-South openness, the efficiency wage is at the vicinity of the full employment wage in the North. So, both skilled and unskilled workers are fully employed. In the North, openness results in a decrease in the full employment wage of unskilled workers that falls below the efficiency wage. As firms enforce the latter, openness comes with the unemployment of unskilled workers in the North.

Finally, openness can modify the reference wage. This is particularly the case (i) when this wage depends negatively on unemployment, and (ii) when it depends positively on the wages during the previous periods. Then, by generating unemployment openness diminishes the reference wage, and this reduction is subsequently self-reinforcing. Openness is now both inequality and unemployment enhancing.

\section{Technological differences and technical change}

One of the most controversial assumptions concerning the NS-HOS model is that both countries share identical technologies. This assumption can be justified by the internationalisation of firms within a world economy in which physical capital and technologies are (almost) perfectly mobile. Thus, northern firms can produce in the South with northern technologies. Albeit so, there are several reasons why a technological gap may

\footnotetext{
${ }^{2}$ In several models, the efficiency wage differs according to the sector because the effort functions are not alike in both sectors.
} 
persist between the North and the South: (i) the efficiency of a technology increases with its utilisation because of adaptation processes, skill adjustment of the workers, learning by doing etc., (ii) firms productivity does not solely depend on the technology they use, but also on their environment (access to communication means, quality of available intermediate goods, enforcement of the contracts and rules, social and political risks etc.). Thus, the adjustment to new imported technologies requires time and investments, which indicates that the resulting increase in productivity is a dynamic process.

There are thus a number of reasons that keep productivity lower in the South than in the North. In this section, we firstly examine the case in which the South suffers a productivity gap that is identical in both sectors $h$ and $l$. We subsequently explore the impacts (i) of technological transfers from the North to the South, (ii) of the South's technological catching up, and (iii) of a skill-oriented technological bias.

\subsection{A productivity gap identical in both sectors}

The technological gap, identical in both sectors, consists of differences in total factor productivity (TFP). The country-specific technologies are $Y_{j}=A_{j}^{N} L_{j}{ }^{\alpha_{j}} H_{j}{ }^{1-\alpha_{j}}, j=h, l$, in the North and $Y_{j}=A_{j}^{S} L_{j}{ }^{\alpha_{j}} H_{j}{ }^{1-\alpha_{j}}$ in the South with $A_{j}^{S}=\zeta \times A_{j}^{N}, 0<\zeta<1$. The fact that the depreciation factor $\zeta$ is the same for both $h$ and $l$ indicates that the productivity gap is identical in both sectors.

The production function being homogenous of degree 1, the southern technologies can be written $Y_{j}=A_{j}^{S} L_{j}{ }^{\alpha_{j}} H_{j}{ }^{1-\alpha_{j}}=A_{j}^{N} \tilde{L}_{j}{ }^{\alpha_{j}} \tilde{H}_{j}{ }^{1-\alpha_{j}}$, with $\tilde{L}_{j}=\zeta L_{j}<L_{j}$ and $\tilde{H}_{j}=\zeta H_{j}<H_{j}$ being the northern-efficiency-equivalent unskilled and skilled labour utilised in the South. Thus, by rewriting the production function in terms of northern-efficiency-equivalent labour, we can come back to the usual NS-HOS model, and thereby apply its main results. In particular, factor price equalisation occurs for northern-efficiency-equivalent skilled and unskilled labour, with the world skill premium in terms of northern efficient labour:

$$
\tilde{\omega}_{W}=\frac{1-\alpha}{\alpha} \times \frac{\bar{L}_{N}+\zeta \bar{L}_{S}}{\bar{H}_{N}+\zeta \bar{H}_{S}}
$$

Let $w_{H}^{N}$ and $w_{L}^{N}$ be respectively the unit wages of skilled and unskilled labour in the North, and $w_{H}^{S}$ and $w_{L}^{S}$ those in the South. FPE entails that $w_{H}^{N}$ and $w_{L}^{N}$ are the unit wages of southern skilled and unskilled labour measured in terms of northern efficiency. Thus, one unit of $\tilde{L}=\zeta L$ is paid $w_{L}^{N}$ and one unit of $\tilde{H}=\zeta H$ is paid $w_{H}^{N}$, which results in $L$ and $H$ being paid $w_{L}^{S}=\zeta w_{L}^{N}<w_{L}^{N}$ and $w_{H}^{S}=\zeta w_{H}^{N}<w_{H}^{N}$ in the South. As a consequence:

1) Both skilled and unskilled workers are better paid in the North than in the South.

2) The skill premium is the same in the North and the South and equal to the world value given by Relation (6).

By assuming a technological gap that is identical in both sectors, the extension of the NSHOS model provides an explanation for the observed higher wages in the North compared to the South for both skilled and unskilled workers (stylised fact 9). It however fails to explain the lasting difference in skill premia between the two areas with inequality being permanently higher in the South (stylised fact 11). It must however be underlined that both stylised facts 9 
and 11 can be explained by combining a technological gap identical in both sectors with the assumption that the countries are not both inside the D-cone.

\subsection{Technological caching-up}

The productivity gap is identical in both sectors (as in Section 6.1.) but we now suppose that this gap tends to shrink with time because the South learns how to utilise the technologies imported from the North more efficiently. This is very simply modelled as an increase in $\zeta$ that tends towards 1 and makes thereby the South's TFPs tend towards the northern TFPs. As $\bar{L}_{S} / \bar{H}_{S}>\bar{L}_{N} / \bar{H}_{N}$, this brings an increase in the world skill premium $\tilde{\omega}_{W}=\frac{1-\alpha}{\alpha} \times \frac{\bar{L}_{N}+\zeta \bar{L}_{S}}{\bar{H}_{N}+\zeta \bar{H}_{S}}$ that tends towards $\hat{\omega}_{W}=\frac{1-\alpha}{\alpha} \times \frac{\bar{L}_{N}+\bar{L}_{S}}{\bar{H}_{N}+\bar{H}_{S}}$. In fact, the increase in $\zeta$ is equivalent to an increase in the size of the South.

Two cases can be distinguished:

1) If the South is inside the D-cone, technological catching up raises the world equilibrium skill premium, which results in growing inequality in both the North and the South. At the same time, the increase in the TFPs causes the real wages to rise in the South and the increase in the skill premium raises the relative price $p_{h} / p_{l}$ (and thus the North's terms of trade), which fosters the production of $l$.

2) If the South is outside the D-cone, the increase in its TFPs causes it to produce more goods $l$, and the increase in the South's real income hikes its demand for both $l$ and $h$. As (i) the increase in the production of $l$ is larger than the increase in the demand for $l$ (because the South accounts for a limited share of this demand), and (ii) there is an increase in the demand for $h$ by the South with good $h$ being fully produced in the North, this results in a larger proportion of $l$ being produced in the South and a substitution of $h$ for $l$ in the North's production. The related increase in the demand for skilled labour induces a rise in the North's skill premium and inequality.

The introduction of technological catching up reinforces the rise in inequality in the North and it makes this rise into a dynamic process. For the North, the South's catching up is equivalent to the South growing in size. In the South, technological catching up increases inequality if this area is inside the D-cone, and it has no impact upon inequality when the South is outside.

\subsection{Technological transfer}

As already mentioned, North-South openness combined with the internationalisation of firms typically leads to technological transfers from the technologically advanced economy (the North) to the technologically delayed economy (the South). In addition, there are several reasons to assume that, prior to openness, northern technologies had been more skill intensive than southern technologies. A major reason for this comes from the differences in skill endowments. Since the North is highly endowed with skilled workers, the relative price of skilled labour is lower there and R\&D is thus oriented towards skill intensive technologies (Acemoglu, 1998). As a consequence, technological transfers from the North to the South do not only result in an increase in total factor productivity in the South, but also in an upward move in its skill intensities.

In the HOS approach developed here, a technology-driven increase in the southern skill intensities is modelled by a downward move of the coefficients $\alpha_{j}, j=h, l$, from the southern 
technology values $\alpha_{j}^{S}$ to the northern technology values $\alpha_{j}^{N}<\alpha_{j}^{S}$. Thus, North-South openness makes the southern skill premium move from $\underline{w}_{S}=\frac{1-\alpha_{S}}{\alpha_{S}} \bar{\lambda}_{S}$, with $\alpha_{S}=\beta \alpha_{l}^{S}+(1-\beta) \alpha_{h}^{S}$, to:

1) $\bar{w}_{S}=\hat{w}_{W}=\frac{1-\alpha_{N}}{\alpha_{N}} \bar{\lambda}_{W}$ with $\alpha_{N}=\beta \alpha_{l}^{N}+(1-\beta) \alpha_{h}^{N}$ if both countries are inside the diversification cone, and

2) $\bar{w}_{S}{ }^{\prime}=\frac{1-\alpha_{l}^{N}}{\alpha_{l}^{N}} \bar{\lambda}_{S}$ if the South is outside the D-cone and produces thereby good $l$ only with the northern technology.

In contrast with the traditional NS-HOS approach, there is now room for an increase in inequality (the skill premium) in the South. This occurs in two cases:

1) if $\bar{w}_{S}=\frac{1-\alpha_{N}}{\alpha_{N}} \bar{\lambda}_{W}>\underline{w}_{S}=\frac{1-\alpha_{S}}{\alpha_{S}} \bar{\lambda}_{S}$, both countries being inside the D-cone for the northern technology. Here, the decrease in inequality due to $\bar{\lambda}_{W}<\bar{\lambda}_{S}$ is dominated by the increase in inequality due to the rise in skill intensity generated by the technological transfer that makes $\frac{1-\alpha_{S}}{\alpha_{S}}$ shift to $\frac{1-\alpha_{N}}{\alpha_{N}}>\frac{1-\alpha_{S}}{\alpha_{S}}$.

2) if $\bar{w}_{S}{ }^{\prime}=\frac{1-\alpha_{l}^{N}}{\alpha_{l}^{N}} \bar{\lambda}_{S}>\underline{w}_{S}=\frac{1-\alpha_{S}}{\alpha_{S}} \bar{\lambda}_{S}$, the South being outside the D-cone for the northern technology. The condition for this is $\alpha_{l}^{N}<\alpha_{S}=\beta \alpha_{l}^{S}+(1-\beta) \alpha_{h}^{S}$.

In both cases, the impact of openness upon inequality in the South crucially depends on the strength of the increase in skill intensity due to technological transfers from the North. The South may experience higher or lower inequality depending on the move in skill intensity and, when both areas are in the D-cone, on the difference of skill endowments between the North and the South. This can provide an explanation to the miscellaneous evidence concerning the link between globalization and inequality in emerging countries.

\subsection{Technological bias}

The explanation of growing inequalities in the North has been dominated by the 'North-South trade versus technological bias' debate (see the review article of Chusseau et al., 2008). There are two types of technological bias. A factor bias is defined by a technological change that increases the relative demand for skilled labour $H / L$ in all industries for a given skill premium. With the Cobb-Douglas technologies selected here, it features of a decrease in both $\alpha_{h}$ and $\alpha_{l}$. A sector bias results from an increase in total factor productivity (TFP) that is higher in skill-intensive industries than in unskilled-intensive ones. Here, it consists of an increase in $A_{h} / A_{l}$. It can be shown that the condition for an $h$-oriented sector bias to increase the skill premium is that the elasticity of substitution in the demand for goods is higher than $1 .^{3}$

\footnotetext{
${ }^{3}$ A sector bias has two effects. On the one hand, it lowers the relative price of good $h$, which entails a rise in the relative demand for this good and thereby a rise in the relative demand of the factor in which $h$ is intensive, i.e. a rise in $H / L$. On the other hand, the increase in TFP reduces the demand for factors and this reduction is more
} 
If both biases can explain the increase in the skill premium, they obviously cannot account for the aforementioned characteristics of globalization. In contrast, they can easily be inserted into the NS-HOS framework. In particular, introducing a factor bias in the NS-HOS typically reinforces inequality and it provides an explanation for the increase in the skill intensity in the North (stylised fact 5).

In the simple model developed here, a sector bias cannot raise the skill premium and inequality. This is because the chosen utility function results in the elasticity of substitution being 1. In contrast, it can explain the decrease in the relative price of skill-intensive goods (Relation 2) $\frac{p_{h}}{p_{l}}=\frac{A_{l}}{A_{h}} \frac{\alpha_{l}^{\alpha_{l}}}{\alpha_{h}^{\alpha_{h}}} \frac{\left(1-\alpha_{l}\right)^{1-\alpha_{l}}}{\left(1-\alpha_{h}\right)^{1-\alpha_{h}}} \hat{\omega}^{\alpha_{l}-\alpha_{h}}$ if the decrease in $A_{l} / A_{h}$ is large enough to offset the increase in the skill premium $\hat{\omega}$.

Finally, in contrast with the debate carried out in the nineties, both globalization and technological bias should be combined rather than opposed so as to generate the main characteristics of the observed changes in the demand and utilisation of skilled and unskilled labour and in inequality.

\section{International outsourcing}

One major observed characteristic of globalization is that multinational firms tend to locate their different stages of production according to the cost advantage of each country (stylised fact 3). In the economic literature, this characteristic is called international outsourcing or offshoring (both terms being henceforth synonymous) and it has generated a large number of theoretical and empirical contributions.

The traditional HOS framework cannot portray such behaviour because it assumes no segmentation of production. In this model, one unit of good is always fully produced in one country. The introduction of intermediate goods into HOS frameworks is long-standing (Batra \& Casas, 1973; Dixit \& Grossman 1982) and the explicit account of segmentation and offshoring is exposed in Jones \& Kierzkowski (1990). Most of the works in this vein, including Jones \& Marjit (1992), Jones \& Kierzkowski (2000), Findlay \& Jones (2000, 2001), Jones, Kierzkowski \& Leonard (2002), provide rather ambiguous findings since offshoring of the labour intensive stage of production can give rise to both lower or higher wage depending on the considered configuration. This ambiguity is confirmed by the literature that inserts segmentation into HOS general equilibrium models (Deardorff, 1989a and b; Venables, 1999; Markusen, 2005).

In this section, we do not review this literature. We only describe a very simple segmentation-extended NS-HOS framework that generates an increase in both the skill premium and the skill intensities in the North.

\subsection{Segmentation and international outsourcing: Definitions}

A production process is segmented if it can be divided into several segments that are combined to produce the final good. A simple $n$-segment production process can be modelled by:

$$
Y=G\left(x_{1}\left(H_{1}, L_{1}\right), x_{2}\left(H_{2}, L_{2}\right), \ldots, x_{n}\left(H_{n}, L_{n}\right)\right)
$$


where $x_{i}\left(H_{i}, L_{i}\right), i=1 \ldots n$, is the $i$-th segment and function $G(\bullet)$ represents the way the different segments are combined.

Of course, segmentation can take more complex forms, in which several levels of segmentation can coexist and combine.

The segmented production process (7) can be represented by the integrated production function $F(H, L)$ if at the firm's optimum:

$$
G\left(x_{1}\left(H_{1}, L_{1}\right), x_{2}\left(H_{2}, L_{2}\right), \ldots, x_{n}\left(H_{n}, L_{n}\right)\right)=F(H, L), \quad L=\sum_{i=1}^{n} L_{i} \text { and } H=\sum_{i=1}^{n} H_{i}
$$

Most of the segmented production processes cannot be represented by an integrated function. However, when function (7) consists of a Cobb-Douglas combination of CobbDouglas functions, it can be shown that this is possible. In the case of two segments, the segmented process $Y=a\left(L_{1}^{\alpha} H_{1}{ }^{1-\alpha}\right)^{\gamma}\left(L_{2}{ }^{\beta} H_{2}{ }^{1-\beta}\right)^{1-\gamma}$ can be represented by the integrated production function $Y=A L^{\delta} H^{1-\delta}$ where $L=L_{1}+L_{2}, H=H_{1}+H_{2}, \delta=\gamma \alpha+(1-\gamma) \beta$ and $A=a \frac{\left(\gamma \alpha^{\alpha}(1-\alpha)^{1-\alpha}\right)^{\gamma}\left((1-\gamma) \beta^{\beta}(1-\beta)^{1-\beta}\right)^{1-\gamma}}{\delta^{\delta}(1-\delta)^{1-\delta}}$.

Finally, international outsourcing (offshoring) occurs when the different segments of a production process are located in different countries. This location obviously depends on the cost of producing, i.e., on the comparative advantages of each country

\subsection{Segmentation in the NS-HOS model}

From the above characteristics, it is possible to introduce segmentation into the NS-HOS model. For this, the model must be transformed from a $2 \times 2 \times 2$ into a $2 \times 2 \times 2 \times 2$ framework, i.e., 2 factors $\times 2$ segments $\times 2$ goods $\times 2$ countries. A new stage of production is thus added to the initial model.

The two segments $h$ and $l$ are combined to produce final goods in both sectors $h$ ' and $l$ '.

Segment $h$ is $H$-intensive, and segment $l$ is $L$-intensive. Sector $h$ ' is $h$-intensive and sector $l$ ' is $l$-intensive. With Cobb-Douglass technologies, the segmentation-augmented NS-HOS approach can thus be modelled by assuming the following production functions (TFP is omitted for the sake of simplicity):

- For the segments $h$ and $l$ :

$$
Y_{h}=L_{h}{ }^{\alpha_{h}} H_{h}{ }^{1-\alpha_{h}} \text { and } Y_{l}=L_{l}{ }^{\alpha_{l}} H_{l}{ }^{1-\alpha_{l}} \text {, with } \alpha_{l}>\alpha_{h} \text {. }
$$

- For the final goods $h^{\prime}$ and $l^{\prime}$ :

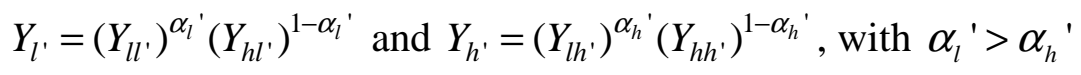

$Y_{i j}$ being the quantity of intermediate good $i$ utilised for the production of the final good $j$.

This framework portrays the following production scenario. The $H$-intensive upstream stage of production consists of segment $h$ (with function $Y_{h}=L_{h}{ }^{\alpha_{h}} H_{h}{ }^{1-\alpha_{h}}$ ) whereas the downstream assembling stage consists of the combination of segment $l$ and the final production function, i.e. function $Y_{i}=\left(L_{l i}{ }^{\alpha_{l}} H_{l i}{ }^{1-\alpha_{l}}\right)^{\alpha_{i}}\left(Y_{h i}\right)^{1-\alpha_{i}}, i=h^{\prime}, l^{\prime}$. We also suppose that segments are sector-specific, which means that there are four segments but only two segment 
production functions. Thus, each segment is accounted for in the final good sector to which it belongs.

By applying the features depicted in sub-section 7.1, the final goods production functions corresponding to the firms' optimum can be written:

$$
\begin{aligned}
& Y_{l^{\prime}}=A_{l^{\prime}}\left(L_{l^{\prime}}\right)^{\delta}\left(H_{l^{\prime}}\right)^{1-\delta} \\
& Y_{h^{\prime}}=A_{h^{\prime}}\left(L_{h^{\prime}}\right)^{\eta}\left(H_{h^{\prime}}\right)^{1-\eta}
\end{aligned}
$$

with $L_{h^{\prime}}=L_{l h^{\prime}}+L_{h h^{\prime}}, H_{h^{\prime}}=H_{l h^{\prime}}+H_{h h^{\prime}}, L_{l^{\prime}}=L_{l l^{\prime}}+L_{h l^{\prime}}, H_{l^{\prime}}=H_{l l^{\prime}}+H_{h l^{\prime}}, \eta=\alpha_{l} \alpha_{h}{ }^{\prime}+\alpha_{h}\left(1-\alpha_{h}{ }^{\prime}\right)$, $\delta=\alpha_{l} \alpha_{l}{ }^{\prime}+\alpha_{h}\left(1-\alpha_{l}{ }^{\prime}\right), \quad A_{h^{\prime}}=\frac{\left(\alpha_{h}{ }^{\prime} \alpha_{l} \alpha_{l}\left(1-\alpha_{l}\right)^{1-\alpha_{l}}\right)^{\alpha_{h}{ }^{\prime}}\left(\left(1-\alpha_{h}{ }^{\prime}\right) \alpha_{h}^{\alpha_{h}}\left(1-\alpha_{h}\right)^{1-\alpha_{h}}\right)^{1-\alpha_{h}{ }^{\prime}}}{\eta^{\eta}(1-\eta)^{1-\eta}} \quad$ and $A_{l^{\prime}}=\frac{\left(\alpha_{l}{ }^{\prime} \alpha_{l}^{\alpha_{l}}\left(1-\alpha_{l}\right)^{1-\alpha_{l}}\right)^{\alpha_{l^{\prime}}}\left(\left(1-\alpha_{l}{ }^{\prime}\right) \alpha_{h}^{\alpha_{h}}\left(1-\alpha_{h}\right)^{1-\alpha_{h}}\right)^{1-\alpha_{l^{\prime}}}}{\delta^{\delta}(1-\delta)^{1-\delta}}$. It can be easily verified that $\delta>\eta$, i.e., $\operatorname{good} h^{\prime}$ is logically $H$-intensive and good $l^{\prime} L$-intensive.

To determine the wages (factor prices), the prices of final goods as well as the amount of each factor $H$ and $L$ utilised for the production of each final good $h^{\prime}$ and $l$, one can thus disregard segmentation and directly calculate the equilibrium from the final production functions (11) and (12).

However, when the analysis is implemented in North-South openness, $L_{h^{\prime}}, H_{h^{\prime}}, L_{l^{\prime}}$ and $H_{l}$, are the factor utilised at the world level in the productions of final goods, and we cannot infer from these the amount of skilled and unskilled labour utilised by each sector in each country, i.e., the skill intensities in sectors $h^{\prime}$ and $l$ '.

\subsection{Factor intensities}

Free and costless offshoring results in the specialisation of each country within the segment for which it displays a comparative advantage. Thus, the usual results of the NS-HOS model are valid for the production in each segment. Following their relative endowments, the North and the South are respectively specialised in segments $h$ and $l$. In the North, openness causes an increase the skill premium (inequality) and hence a decrease in skill intensities in both segments $h$ and $l$.

In each country, each domestic segment is accounted for in the sector it belongs to, and thus each domestic factor is accounted for in the sector that utilises the domestic segment this factor produces. Consequently, in each country, there is a clear difference between the factors utilised in the production of final goods (these factors can be either domestic or imported) and the utilisation of domestic factors in each sector. More precisely:

1) A final good is produced at the downstream stage by the production function $Y_{i}=\left(L_{l i}{ }^{\alpha_{l}} H_{l i}{ }^{1-\alpha_{l}}\right)^{\alpha_{i}}\left(Y_{h i}\right)^{1-\alpha_{i}}, i=h^{\prime}, l^{\prime}$, in which $Y_{h i}$ can be, either domestically produced, or imported. Thus, the factors utilisation in the production of final goods in one country comprises both the factors that are included in the domestically produced segments and those included in the imported part of segment $Y_{h i}$.

2) Part of the segment $Y_{h i}$ produced in the North is exported to the South. This is not utilised in the North for the final production of goods, but it is accounted for in the North as belonging to the sector $i=h^{\prime}, l^{\prime}$ by which it is utilised. 
3) Thus, the final production $Y_{i}=\left(L_{l i}{ }^{\alpha_{l}} H_{l i}{ }^{1-\alpha_{l}}\right)^{\alpha_{i}}\left(Y_{h i}\right)^{1-\alpha_{i}}$ of good $i=h^{\prime}, l^{\prime}$ in one country utilises the domestic factors $L_{l i}$ and $H_{l i}$ as well as all the factors, domestic and incorporated into imports, utilised for the upstream stage $Y_{h i}$. In contrast, the utilisation of domestic factors accounted for in sector $i=h^{\prime}, l^{\prime}$ comprises all the factors incorporated in the domestic production of the segments utilised in this sector, these segment being either bought inside the country or exported. The country factor intensity in each sector $i=h^{\prime}, l^{\prime}$ is measured from these utilisations of domestic factors.

Given that the factors (domestic and foreign) utilised in the domestic production of a final goods differ from the domestic factors utilised in each sector at the world level, and since the latter are those accounted for to measure the factor intensities of each sector in each country, these factor intensities typically differ from the sectoral factor intensities at the world level.

Thus, when North-South openness increases the skill premium in the North, factor intensities at the world level fulfil the usual HOS prediction of lower skill intensities in each sector at the world level compared to the North in autarky. Nevertheless, factor intensities measured in the North may not be higher in all sectors in openness compared to autarky. Of course, if factor endowments in the North remain unchanged, then these intensities cannot increase in both sectors (because full employment is still taking place). However, if skill endowment augments in the North (stylised fact 8), then skill intensities may well increase in both sectors.

In the North, an increase in the skill premium may now come with an increase in skill intensities in both sectors (Stylised fact 5), provided that the North skill endowment increases (stylised fact 8).

It can finally be noted that international outsourcing as modelled here can explain the controversial diagnosis that is made on the specialisation of China in high skill-intensive goods based on the growing exports of computer, communication and electronic goods. If China is specialised in the assembling ( $L$-intensive) stage of high skill-intensive goods (computers), and if the skill intensity that is attributed to China is that of the total production of theses goods, then this measure creates the illusion of a new Chinese specialisation in high skill intensive sectors. Krugman (2008) has underlined the error of making such a diagnosis.

In summary, inserting segmentation inside the NS-HOS model makes it possible (i) to generate international outsourcing and (ii) to engender concomitant increases in the skill premium and in skill intensities in all the final goods sectors in the North when this area experiences an upsurge of its skill endowment. These results are consistent with the stylised facts 3 and 5.

\section{Further extensions}

We now explore certain additional extensions. These are only briefly and partially described for a series of reasons. Firstly, such extensions as the introduction of human capital accumulation into HOS models or the enlargement of the number of goods and factors deserve full chapters in order for them to be accurately appraised. Secondly, certain extensions would lead us far from the initial model and their Heckscher-Ohlinian specificity might be seen as controversial.

Four extensions are discussed. The first concerns the introduction of factor dynamics in the HOS framework, with special emphasis laid upon human capital accumulation. The second extension analyses the impact of skill upgrading on the results determined in the previous sections. Thirdly, the case of capital-skill complementarity is briefly exposed. We finally tackle the question of multiple numbers of goods and factors by focusing on the case of a continuum of goods. 


\subsection{Factor dynamics in the HOS model}

Since the original article of Onika \& Uzawa (1965) who inserted capital dynamics within a $2 \times 2 \times 2$ HOS model, a large literature has explored the dynamics of factor endowments and their impacts on trade, especially within overlapping generation models (e.g.: Gale, 1971 and 1974; Buiter, 1981; Mountfort, 1998 etc. for models with capital and labour). Within a $2 \times 2 \times 2$ HOS model with capital formation depending on an OLG dynamics, multiple steady states and different preferences (savings) between the two countries, Mountford (1998) shows that openness can (i) produce a rise or a fall in the world income per capita at the steady state and (ii) make an economy with a low autarkic per capita GDP steady state to catch up and overtake the GDP per capita of an economy with a higher autarkic per capita GDP steady state. Centred on capital accumulation, these works appear rather inadequate to portray NorthSouth trade based on differences in skill endowments. Human capital accumulation is the appropriate means to introduce dynamics into the North-South HOS model.

Since Findlay \& Kierzkowski (F\&S) seminal article (1983), a number of works have investigated the influence of openness upon skill endowments (see the review of Falvey et al., 2008). By introducing human capital accumulation within a NS-HOS model, Findlay \& Kierzkowski (1983) show that openness enlarges the skill differences between countries. As openness increases the return to human capital in the North and reduces it in the South, northern workers are encouraged, and southern workers discouraged, to invest in human capital. This fosters human capital accumulation in the North, and lowers it in the South. Within a similar framework, Borsook (1986) assumes different abilities among individuals resulting in different lifetime earnings of skilled and unskilled workers at equilibrium. Then openness boosts education in the North as in F\&K analysis, but, in contrast with F\&K, this also increases inequality in the North. The F\&K and Borsook findings are based on two effects. The Stolper-Samuelson effect increases inequality (the skill premium) through the rise in the relative price of the skill intensive good. The Findley-Kierzkowski effect narrows inequality by raising the supply of skilled labour in the North, but it can also promote it by lowering skill accumulation in the South. Falvey et al. (2010) analyse the impacts of trade liberalisation upon a small Northern economy within a HOS framework augmented by an educational sector that utilises skilled labour. Individuals with different abilities can choose to get educated throughout their working lives. The paper focuses on the transitional dynamics generated by the imports of unskilled intensive goods. Trade liberalisation encourages the younger and the more able unskilled workers to become skilled. Moreover, this move does not take place at the same time for all individuals, depending on the age and on whether the trade shock is anticipated or not. Finally, trade expansion leads to both skill upgrading and higher inequality.

Several theoretical works have come to the opposite conclusion that trade encourages the convergence in human capital endowments (Cartiglia, 1997; Eicher, 1999). This essentially derives from the fact that skilled labour is the main factor utilised in education. By increasing the cost of education in the North and reducing it in the South, openness reduces human capital accumulation in the North and fosters it in the South. When the credit market is imperfect, the negative (positive) effect in the North (the South) is amplified (Cartiglia, 1997). Imperfection in the credit market is a key element in a number of analyses. For instance, Ranjan (2001) come to the conclusion that trade liberalisation can increase human capital accumulation in both the North and the South when credit-market imperfections are low in the former and high in the latter. In Ranjan (2003), a country with a low-income autarkic steady state that trades with another with a high-income steady state can converge towards this high 
income steady state. This derives from the rise in the wage of unskilled workers that releases the constraint upon human capital accumulation.

In summary, the theory provides rather ambiguous predictions of the influence of openness upon skill endowments and inequality in both the North and the South. Four effects with different impacts are at work. The Stolper-Samuelson effect widens inequality in the North and reduces it in the South. The Findley-Kierzkowski effect fosters education and skill in the North and discourages them in the South, resulting in opposite impacts upon skill and inequality at the world level. The cost of education effect reduces education in the North and promotes education in the South, having thereby opposite impacts upon the world skill endowment. Finally, imperfections on the credit market counteract the Findley-Kierzkowski effect by obstructing the openness-driven skill upgrading in the North and releasing the constraint upon education in the South. The final outcome in terms of skill endowments and inequality depends on the combination of these four effects and thus on their respective weights.

\subsection{The impact of skill upgrading}

We now briefly explore the impact of skill upgrading upon the results determined in Sections 3-7, regardless of whether this increase results from private decisions of households or from pro-education public policies. The increase in skill endowment can occur in the North, in the South or in both countries at the same time.

When the skill endowment of the North increases, this results in lower inequality in the North regardless of whether both countries produce both goods or not. In addition, this also decreases inequality in the South when both countries produce both goods.

When the southern skill endowment increases, this narrows inequality in the South regardless of whether both countries produce both goods or not, and it reduces inequality in the North when both countries produce both goods.

Finally, when wage rigidities (minimum wage or efficiency wage) lead to unemployment of the unskilled in the North, skill upgrading in the North reduces unemployment, and skill upgrading in the South has the same impact if it causes the world skill premium to dip below the value corresponding to the minimum or the efficiency wage.

\subsection{Capital skill complementarity}

When physical capital $K$ is added as a third factor of production, the relative demand for skilled labour $H / L$ can depend on the demand for, and the utilisation of, capital. This is the case when, following Griliches (1969) hypothesis, there is capital-skill complementarity (henceforth CSC) in the production function. There is relative CSC when capital is more substitutable for unskilled than for skilled labour. There is absolute CSC if an increase in the utilisation of capital comes with an increase in the utilisation of skilled labour.

Relative CSC corresponds to production functions with an elasticity of substitution between $K$ and $L$ that is higher than the elasticity of substitution between $\mathrm{K}$ and $\mathrm{H}$. In this case, a decrease in the price of capital $K$ compared to both skilled and unskilled labour increases the relative demand $H / L$ because the demand for $L$ decreases more than the demand for $H$.

Let us suppose now that the production of capital is segmented into two stages, i.e., one skill intensive stage that produces high-tech components and an unskilled-intensive assembling stage. International outsourcing signifies that the latter stage is relocated to the South where unskilled labour is significantly inexpensive. This corresponds to no factor price equalisation between the North and the South. In the North, international outsourcing lowers 
the cost of capital goods compared to both skilled and unskilled labour. With absolute CSC, the absolute demand for $H$ increases, and thus the relative demand $H / L$. With relative CSC, there is a decrease in both demands for both $H$ and $L$, but the relative demand $H / L$ increases. In both cases, the rise in $H / L$ pushes the skill premium up.

Thus, the combination of CSC with international outsourcing of the assembling stage of capital goods reinforces the Stolper-Samuelson effect in the North by fostering the demand for skilled labour.

In the South, CSC can also encourage inequality. Suppose that North-South openness results in the South adopting more capital-intensive technologies, particularly for the production of components exported to the North. Then, CSC brings about an increasing demand for skilled labour and a rise in the skill premium. This mechanism has been underlined by Cragg \& Epelbaum (1996) for Mexico and Behrman et al. (2000) for Latin America.

\subsection{The NS-HOS model with a continuum of goods}

In its traditional presentation, the NS-HOS framework assumes two goods and two factors. Increasing the number of goods and/or factors can substantially modify the outcomes. By adding capital to skilled and unskilled labour, CSC already extends the number of factors. Here, the analysis is restricted to NS-HOS approaches with a continuum of goods.

Following the seminal article of Dornbush, Fisher \& Samuelson (1980), a number of works have explored the impacts of extending the HOS model by assuming a continuum of goods (see, e.g.: Xu, 1993; Zhu, 2001 and 2004; Romalis, 2004; Xiang, 2007; Hellier \& Chusseau, 2010). As regards growing inequality between skilled and unskilled workers, the NS-HOS approach with a continuum of goods provides several paths through which the skill premium can augment:

1. When new skill-intensive goods are created and produced in the North, this raises the relative demand for skilled labour and thereby the skill premium. This mechanism was firstly modelled by Zhu (2001) within a NS-HOS framework with log-linear preferences. It has subsequently been extended by Xiang (2007) who (i) shows that even unskilled intensive new northern goods can raise the northern skill premium, and (ii) explores the case of CES preferences.

2. When the size of the South increases, this area produces a growing number of more skill-intensive goods. This raises the skill premium in both the South and the North. This mechanism is at the base of the Hellier \& Chusseau (2010) model showing that the growing size of the South creates an inequality-unemployment trade-off that is more intense in inequality-oriented northern countries than in equality-oriented ones. We now expose a simple diagrammatic presentation that makes it possible to synthesize this mechanism.

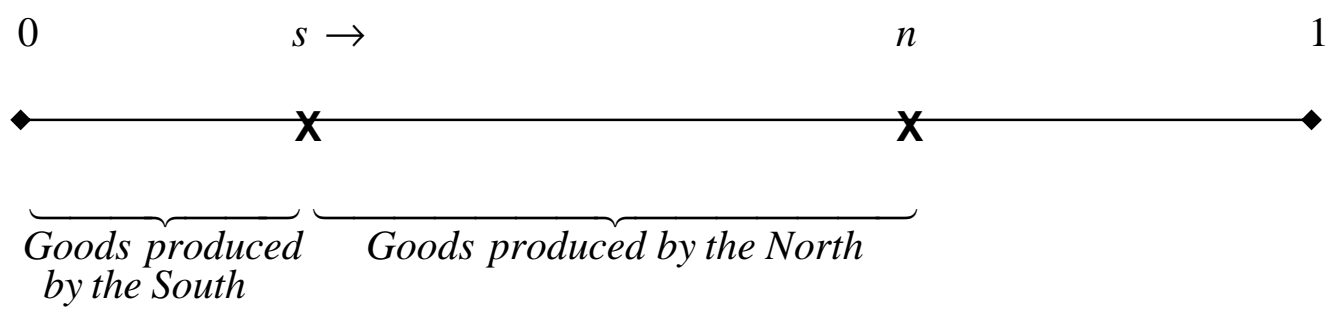

Figure 6. NS-HOS framework with a continuum of goods 
We assume a NS-HOS model with a continuum of goods over interval $[0, n], n<1$, with good $i \in[0, n]$ being produced according to the Cobb-Douglas technology $Y_{i}=\left(L_{i}\right)^{1-i}\left(H_{i}\right)^{i}$. The utility function is $u=\int_{0}^{n} \log x d x$ so that each good has the same weight in the households' expenditure. We finally suppose that the countries endowments are sufficiently different so that, at full employment, the South produces goods $[0, s]$ and the North goods $[s, n]$. Good $s$ is thus the only one produced by both countries. Figure 6 depicts this general framework.

Let us firstly suppose that the North creates new goods, i.e., an increase in $n$ and thereby in the set of goods $[0, n]$. Since the new goods are the most skill intensive, they are produced in the North and, for given labour endowments of both the North and the South, the increase in $n$ results in an increase in $s$. A shift from $n$ to $n^{\prime}>n$ entails a shift of $s$ to $s^{\prime}>s$, making the following changes in the production sets: from $[0, s]$ to $\left[0, s^{\prime}\right]$ for the South and from $[s, n]$ to $\left[s^{\prime}, n^{\prime}\right]$ for the North. In both countries, production experiences an upward move on the skill intensity ladder, resulting in higher demand for skilled labour and an increase in the skill premium (inequality). In addition, the rise in the demand for skilled labour and the related increase in the skill premium are typically higher in the North than in the South. This is because the rise in skill intensity solely concerns the upper side of the production set in the South (the upper limit moves from $s$ to $s^{\prime}$ ), whereas it affects both the lower and the upper sides of the production sets in the North.

Let us assume now that the number of goods $n$ is constant and that globalisation results in a growing size of the South, causing threshold $s$ to move to the left (Figure 6). In this case:

1. The southern production becomes more skill intensive because it corners more skill intensive goods, which raises the skill premium and inequality in the South.

2. The northern production becomes more skill intensive because it loses its less skill intensive goods, which raises the skill premium and inequality in the North.

3. If the North prevents the increase in inequality (the skill premium), this causes unemployment of the less skilled. Thus, the increasing size of the South generates an inequality unemployment trade-off.

4. In addition, if there are several northern countries with different skill premia, Hellier \& Chusseau (2010) have shown that the more egalitarian the country at the outset of globalisation, the lower the intensity of the inequality unemployment trade-off.

In summary, when assuming a continuum of goods within the NS-HOS model, both the creation of new skill intensive goods and the growing size of the South increase inequality in both the North and the South. There is however a difference between the two explanations when the North comprises several countries with different skill premia (e.g., based on different labour market institutions), and thus different orientation towards inequality. In the case of the growing size of the South (increase in $s$ with $n$ remaining unchanged), the more egalitarian a northern country, the more affected it is by the inequality-unemployment tradeoff. This is because inequality-oriented countries must change their specialisation more than egalitarian ones. It can be shown that a creation of new skill-intensive goods (increase in $n$ with $s$ constant) produces the opposite impact: it affects more the egalitarian northern countries than the inequality-oriented ones because then the change in specialisation is more intense in the former than in the latter. 


\section{General assessment and conclusion}

From the initial diagnosis that the predictions of the traditional NS-HOS model are to a large extent at variance with observed developments, this model has been modified and extended in several ways:

1) By assuming a growing size of the South and large differences in factor endowments so that both countries are not inside the diversification cone;

2) By assuming rigidities on the labour markets such as a minimum wage and efficiency wages;

3) By inserting several types of technological differences between the North and the South, technological catching-up and technological biases;

4) By introducing segmentation and international outsourcing.

Table 4 relates each extension to the highlighted stylised facts. Each extension discards one or several initially diagnosed contradictions, and their combination renders the model compatible with all the stylised facts listed in Section 2. In addition, several extensions result in ambiguous impacts in terms of certain observed facts because they can generate them or not depending on the configuration, which is indicated by 'yes/no' in the table.

Logically, the different types of extension are adapted to different shortcomings of the traditional NS-HOS approach. Introducing the D-cone makes it possible to generate full specialisation in production. Labour market rigidities generate unemployment and the inequality-unemployment trade-off. The introduction of technological change permits to account for changes in prices and in factor demand and utilisation.

The crucial role of technology to bring the NS-HOS framework closer to the stylised fact must be underlined. Firstly, technology acts through several channels: technological gaps between the North and the South, technological transfers, productivity catching-up and technological biases. Secondly, it allows accounting for several significant developments in terms of factor and commodity prices and factor demand and utilisation.

The analysis presented here shows that the NS-HOS framework remain an essential tool to model the observed developments of globalization and inequality under the condition of modifications and extensions that correct its most simplifying and controversial assumptions. This does not mean that globalization is the essential explanation of these changes. It must rather be understood as emphasizing that the combination of, and interactions between, globalisation, institutional changes and technological progress is the most fruitful way to analyse the globalization-inequality relationship. 
Table 4. The extensions of the NS-HOS model facing Stylised facts

\begin{tabular}{|c|c|c|c|c|c|c|c|c|c|c|}
\hline Stylised facts & $\begin{array}{c}\text { Initial } \\
\text { NS- } \\
\text { HOS } \\
\text { model } \\
\end{array}$ & $\begin{array}{l}\text { Outside } \\
\text { the } \\
\text { D-cone }\end{array}$ & $\begin{array}{l}\text { Mini- } \\
\text { mum } \\
\text { wage }\end{array}$ & $\begin{array}{l}\text { Effi- } \\
\text { ciency } \\
\text { wage }\end{array}$ & $\begin{array}{c}\text { Tech. } \\
\text { gap alike } \\
\text { in both } \\
\text { sectors } \\
\end{array}$ & $\begin{array}{l}\text { Tech. } \\
\text { transfer }\end{array}$ & $\begin{array}{c}\text { Produc- } \\
\text { tivity } \\
\text { catching- } \\
\text { up } \\
\end{array}$ & $\begin{array}{c}\text { Factor } \\
\text { techno- } \\
\text { logical } \\
\text { bias } \\
\end{array}$ & $\begin{array}{c}\text { Sector } \\
\text { techno- } \\
\text { logical } \\
\text { bias } \\
\end{array}$ & $\begin{array}{l}\text { Segment } \\
\text { ation }\end{array}$ \\
\hline $\begin{array}{l}\text { 1. The South is specialized in unskilled } \\
\text { intensive goods and the North in skill- } \\
\text { intensive goods }\end{array}$ & yes & yes & yes & yes & yes & yes & yes & n.r & n.r & yes \\
\hline 2. International outsourcing & n.r. & n.r. & n.r. & n.r. & n.r. & n.r. & n.r. & n.r. & n.r. & yes \\
\hline $\begin{array}{l}\text { 3. Increase in the skill intensity in all } \\
\text { industries in both the North and the } \\
\text { South. }\end{array}$ & no & no & no & no & no & yes & no & yes & no & yes \\
\hline 4. FDIs from the North to the South & n.r. & n.r. & n.r. & n.r. & n.r. & n.r. & n.r. & n.r. & n.r. & yes \\
\hline $\begin{array}{l}\text { 5. Increase in unemployment of unskilled } \\
\text { workers in the North }\end{array}$ & no & no & yes & yes & no & no & no & no & no & no \\
\hline $\begin{array}{l}\text { 6. The wage gap between the North and } \\
\text { the South remains substantial for } \\
\text { unskilled as well as for skilled workers }\end{array}$ & no & no & no & no & yes & yes/no & $\begin{array}{l}\text { yes but } \\
\text { transitional }\end{array}$ & n.r. & n.r. & no \\
\hline $\begin{array}{l}\text { 7. Increase in the skill premium } \\
\text { (inequality) in the North }\end{array}$ & yes & yes & yes/no & yes/no & yes & yes & yes & yes & yes & yes \\
\hline $\begin{array}{l}\text { 8. The skill premium remains higher in } \\
\text { the South than in the North }\end{array}$ & no & yes & yes/no & yes/no & no & no & no & n.r. & n.r & no \\
\hline $\begin{array}{l}\text { 9. No tendency towards international skill } \\
\text { premia equalisation }\end{array}$ & no & yes & yes/no & yes/no & no & no & no & n.r. & n.r. & no \\
\hline $\begin{array}{l}\text { 10. No decrease in the skill premium in } \\
\text { the South }\end{array}$ & no & no & no & no & no & yes & yes/no & n.r. & n.r. & no \\
\hline $\begin{array}{l}\text { 11. No decrease in the prices of the skill- } \\
\text { intensive goods relative to the unskilled } \\
\text { intensive ones in the North }\end{array}$ & no & no & no & no & no & no & no & yes/no & yes & no \\
\hline
\end{tabular}




\section{References}

Acemoglu D. (1998), "Why Do New Technologies Complement Skills? Directed Technological Change and Wage Inequality", Quarterly Journal of Economics, 113, 1055-189.

Agell, J. and Lundborg, P. (1995), "Fair wages in the open economy", Economica, 62, 325-51.

Albert, M. and Merckl J. (2001), "Efficiency wage, unemployment and intersectoral wage differentials in a Heckscher-Ohlin model", German Economic Review, 2, 287-301.

Batra, R.N. and Casas F.R. (1973), "Intermediate Products and the Pure Theory of International Trade: A Neo-Hecksher-Ohlin Framework", American Economic Review, 63(3), 297-311

Behrman J.R., Birdsall N., and Székely M. (2000), "Economic Reform and Wage Differentials in Latin America." IADB Working Paper, no. 435.

Borsook I. (1986) Earnings ability and international trade, Journal of International Economics 22, 281-95

Brecher, R. (1974), "Minimum wage rates and the pure theory of international trade", Quarterly Journal of Economics, 88, 98-116.

Buiter W.H. (1981), "Time preference and international lending and borrowing in an overlapping generations economy model”. Journal of Political Economy 89, 769-797.

Cartiglia, F.: Credit constraints and human capital accumulation in the open economy. Journal of International Economics 43, (1997): 221-236.

Chipman J .S. (1969), "Factor price equalisation and the Stolper-Samuelson theorem", International Economic Review, 10, 399-406.

Chusseau N. and Hellier J. (2012), Inequality in emerging countries, in: Hellier J. and Chusseau N., Growing income inequality (forthcoming), Chapter 2, Palgrave McMillan.

Chusseau, N., Dumont, M., and Hellier J. (2008), Explaining Rising Inequality: Skill-biased Technological Change and North-South Trade. Journal of Economic Surveys 22, 409-457 .

Cragg, M. I. and Epelbaum M., 1996. "Why Has Wage Dispersion Grown in Mexico? Is It the Incidence of Reforms or the Growing Demand for Skills?" Journal of Development Economics, 51(1): 99-116.

Davidson, C., Martin, M., Matusz, S.J. (1988), "The structure of simple general equilibrium models with frictional unemployment", Journal of Political Economy, 96 (6), 1267-93.

Davidson, C., Martin, M., Matusz, S.J. (1999), Trade and search generated unemployment, Journal of International Economics, 48 (2), 271-99.

Davis D.R. (1998), "Does European Unemployment Prop up American Wages? National Labor Markets and Global Trade," American Economic Review 88, 478-494.

Deardorff, A.V. (1998a). "Fragmentation in Simple Trade Models," RSIE Discussion Paper 422, University of Michigan, January. www.spp.umich.edu/rsie/workingpapers/wp.html.

Deardorff, A.V. (1998b). "Fragmentation across cones," RSIE Discussion Paper 427, August, www.spp.umich.edu/rsie/workingpapers/wp.html

Desjonquères T., Machin S. and VanReenen J. (1999), "Another Nail in the Coffin? Or can the trade based explanation of changing skill structures be resurrected?", Scandinavian Journal of Economics, 101(4), 533-54.

Dixit, A. and Grossman G.M. (1982), "Trade and Protection with Multi-Stage Production", Review of Economic Studies, 49(4), 583-94.

Dornbusch R., S. Fisher, and P.A. Samuelson (1980), "Heckscher-Ohlin Trade Theory with a Continuum of Goods," Quarterly Journal of Economics 95(2), 203-224.

Eicher, T. (1999), Trade, development and converging growth rates: dynamic gains from trade reconsidered. Journal of International Economics 48, 179-198.

Egger, H. and U. Kreickemeier (2009), "Firm heterogeneity and the labor market effects of liberalization", International Economic Review 50: 187-216.

Falvey R., Greenaway D. and Silva, J. (2008), Human capital adjustment to Trade, in: Greenaway D., Upward R. and Wright P. Eds., Globalisation and Labour Market Adjustment, Palgrave McMillan, 97-114.

Falvey, R., Greenaway, D., Silva, J.: Trade liberalization and human capital adjustment. Journal of International Economics 81, (2010): 230-239. 
Felbermayr, G., Prat, J., Schmerer, H.-J., 2011. Globalization and labor market outcomes: wage bargaining, search frictions, and firm heterogeneity. Journal of Economic Theory 146 (1), 39-73.

Findlay R. and Jones R. (2000), "Factor bias and technical progress", Economics Letters, 68, 303-308.

Findlay R. and Jones R. (2001), "Input Trade and the Location of Production", American Economic Review, 91(2), 29-33.

Findlay, R. and Kierzkowski, H.(1983), International trade and human capital: a simple general equilibrium model. Journal of Political Economy 91, 957-78.

Gale, D. (1971), "General equilibrium with imbalance of trade", Journal of International Economics, $1,141-58$.

Gale, D., (1974), The trade imbalance story. Journal of International Economics 4, 119-37.

Goldberg P.K. \& Pavcnik N. (2007), Distributional Effects of Globalization in Developing Countries, Journal of Economic Literature, 45, March, 39-82.

Griliches, Z. (1969) Capital-skill complementarity, Review of Economics and Statistics, 51: 465-68

Hellier J. and Chusseau, N. (2010), Globalization and the Inequality-Unemployment Trade-off. Review of International Economics, 15, 1028-1043.

Helpman, E. and Itskhoki, O., (2010), "Labor market rigidities, trade and unemployment", Review of Economic Studies, 77 (3), 1100-37.

Jones, R.W. and Kierzkowski H. (1990), "The Role of Services in Production and International Trade: A Theoretical Framework", in Ronald Jones and Anne Krueger, eds., The Political Economy of International Trade, Basil Blackwell, Oxford.

Jones, R. and Kierzkowski H. (2000). "A Framework for Fragmentation," Tinbergen Institute Discussion Paper, TI 2000-056/2.

Jones, R. and Marjit S. (1992). "International trade and endogenous production structures," in: W. Neuefrind and R. Riezman (eds), Economic Theory and International Trade, Springer-Verlag.

Jones, R., H. Kierzkowski and G. Leonard (2002). "Fragmentation and intra-industry trade," in P. Lloyd and H Lee (eds), Frontiers of research in intra-industry trade, Palgrave Macmillian.

Kreickemeier, U. (2008), "Unemployment in models of international trade", in: Greenaway D, Upward R. and Wright P. Eds., Globalization and labour market adjustment, Palgrave, McMillan, 73-96.

Kreickemeier, U. and Nelson, D. (2006) "Fair wages, unemployment and technological change in a global economy", Journal of International Economics 70: 451-69.

Krugman, P. (1995) "Growing world trade: causes and consequences", Brookings Papers on Economic Activity: Macroeconomics 1: 327-77.

Krugman P. (2008), "Trade and Inequality revisited", Brookings Papers on Economic Activity, Spring, 103-37.

Krugman P. and Lawrence R. (1993), Trade, jobs and wages, NBER Working Paper nb. 4478.

McKenzie L.W. (1955), "Equality of factor prices in world trade", Econometrica 23, 239-57.

Markusen J. (2005), "Modelling the offshoring of white-collar services: from comparative advantage to the new theories of trade and FDI", NBER Working Paper 11827.

Mountford A. (1998), "Trade, convergence and overtaking", Journal of International Economics 46 $167-82$.

Onika, H., Uzawa H., (1965), "Patterns of trade and investment in a dynamic model of international trade", Review of Economic Studies, 32, 15-38.

Oslington, P. (2002), "Factor market linkages in a global economy", Economics Letters 76(1), 85-93.

Ranjan, P.: Dynamic evolution of income distribution and credit-constrained human capital investment in open economies, Journal of International Economics 55, (2001): 329-358.

Ranjan, P.: Trade induced convergence through human capital accumulation in credit-constrained economies. Journal of Development Economics, 72, (2003): 139-162

Romalis, J. (2004), "Factor Proportion and the Structure of Commodity Trade," American Economic Review 94(1), 67-97.

Venables A. (1999), "Fragmentation and multinational production", European Economic Review, 43, 935-45.

Xiang C. (2007), "New goods and the skill premium", Journal of International Economics 71, 13347. 
$\mathrm{Xu}, \mathrm{Y}$. (1993), "A general model of comparative advantage with two factors and a continuum of goods", International Economic Review, 34(2), 365-80.

Zhu, S.C. (2001) Technical Change, international trade and inequality. PhD thesis, University of Toronto.

Zhu, S.C. (2004) "Trade, product cycles, and inequality within and between countries," Canadian Journal of Economics 37(4):1042-60.

\section{APPENDIX. Determination of the skill premium and employment}

To simplify, the subscript indicating the country is omitted.

Because of the utility function, the total demand for $l\left(Y_{l}^{d}\right)$ and $h\left(Y_{h}^{d}\right)$ are $p_{l} Y_{l}^{d}=\beta I$ and $p_{h} Y_{h}^{d}=(1-\beta) I$, with $I=w_{L} L+w_{H} H$ being the country's total income.

Equalising supply $\left(Y_{l}^{s}\right.$ and $Y_{h}^{s}$ ) and demand on both markets yields:

$$
\begin{aligned}
& p_{l} Y_{l}^{s}=\beta\left(w_{L} L+w_{H} H\right) \\
& p_{h} Y_{h}^{s}=(1-\beta)\left(w_{L} L+w_{H} H\right)
\end{aligned}
$$

Because of the production functions, the demands for unskilled labour in both sectors at the firms' optimum are $L_{l}=\alpha_{l} p_{l} Y_{l}^{s} / w_{L}$ and $L_{h}=\alpha_{h} p_{h} Y_{h}^{s} / w_{L}$, and thereby at the country's level:

$$
L^{-}=L_{l}+L_{h}=\alpha_{l} p_{l} Y_{l}^{s} / w_{L}+\alpha_{h} p_{h} Y_{h}^{s} / w_{L}
$$

Inserting (A5) and (A6) into (A7) yields $L=\left(\beta \alpha_{l}+(1-\beta) \alpha_{h}\right) w_{L}^{-1}\left(w_{L} L+w_{H} H\right)$. Hence $\omega \equiv \frac{w_{H}}{w_{L}}=\frac{1-\alpha}{\alpha} \frac{L}{H}$, with $\alpha \equiv \beta \alpha_{l}-(1-\beta) \alpha_{h}$. The full employment skill premium is thus:

$$
\hat{\omega}=\frac{1-\alpha}{\alpha} \frac{\bar{L}}{\bar{H}}
$$

Finally, the demand for unskilled workers resulting from any $\bar{\omega}<\hat{\omega}$ and full employment of the skilled is:

$$
L=\frac{\alpha}{1-\alpha} \bar{\omega} \bar{H}<\bar{L}
$$

Relations (A8) and (A9) apply for each country being in autarky as well as at the world level when both the North and the South are inside the diversification cone. Consequently The world full employment skill premium is $\hat{\omega}_{W}=\frac{1-\alpha}{\alpha} \frac{\bar{L}_{W}}{\bar{H}_{W}}$, with $\bar{H}_{W}=\bar{H}_{N}+\bar{H}_{S}$ and $\bar{L}_{W}=\bar{L}_{N}+\bar{L}_{S}$. 